\title{
Ascl1 Genetics Reveals Insights into Cerebellum Local Circuit Assembly
}

\author{
Anamaria Sudarov, ${ }^{1}$ Rowena K. Turnbull, ${ }^{1}$ Euiseok J. Kim, ${ }^{2}$ Melanie Lebel-Potter, ${ }^{3}$ Francois Guillemot, ${ }^{3}$ \\ and Alexandra L. Joyner ${ }^{1}$ \\ ${ }^{1}$ Developmental Biology Program, Sloan-Kettering Institute, New York, New York 10065, ${ }^{2}$ Department of Neuroscience, University of Texas Southwestern \\ Medical Center, Dallas, Texas 75390, and ${ }^{3}$ Medical Research Council National Institute for Medical Research, London NW7 1AA, United Kingdom
}

Two recently generated targeted mouse alleles of the neurogenic gene Ascl1 were used to characterize cerebellum circuit formation. First, genetic inducible fate mapping (GIFM) with an $A s c l 1^{C r e E R}$ allele was found to specifically mark all glial and neuron cell types that arise from the ventricular zone (vz). Moreover, each cell type has a unique temporal profile of marking with Ascl1 ${ }^{\mathrm{CrEER}}$ GIFM. Of great utility, Purkinje cells (Pcs), an early cohort of Bergmann glia, and four classes of GABAergic interneurons can be genetically birth dated during embryogenesis using Ascl1 ${ }^{C r E R}$ GIFM. Astrocytes and oligodendrocytes, in contrast, express Ascl1 ${ }^{\text {CreER }}$ throughout their proliferative phase in the white matter. Interestingly, the final position each neuron type acquires differs depending on when it expresses Ascl1. Interneurons (including candelabrum) attain a more outside position the later they express Ascll, whereas Pcs have distinct settling patterns each day they express Ascl1. Second, using a conditional Ascl1 allele, we discovered that Ascl1 is differentially required for generation of most vz-derived cells. Mice lacking Ascl1 in the cerebellum have a major decrease in three types of interneurons with a tendency toward a loss of later-born interneurons, as well as an imbalance of oligodendrocytes and astrocytes. Double-mutant analysis indicates that a related helix-loop-helix protein, Ptfla, functions with Ascl1 in generating interneurons and Pcs. By fate mapping vzderived cells in Ascl1 mutants, we further discovered that Ascl1 plays a specific role during the time period when Pcs are generated in restricting vz progenitors from becoming rhombic lip progenitors.

\section{Introduction}

A fundamental question in neural development is how neurons and glia are generated in temporally and spatially restricted manners such that their ultimate settling patterns result in formation of functional circuits. The cerebellum, a primary center for motor coordination, is an ideal system to study this question because of its highly stereotyped cytoarchitecture and protracted period of development (Altman and Bayer, 1997; Sillitoe and Joyner, 2007). We have used the powerful technique of genetic inducible fate mapping (GIFM) (Joyner and Zervas, 2006; Legué and Joyner, 2010) combined with conditional ablation of the gene encoding the basic helix-loop-helix (bHLH) transcription factor Ascl1 to gain novel insights into development of the cerebellar microcircuitry.

Received Jan. 27, 2011; revised June 10, 2011; accepted June 13, 2011.

Author contributions: A.S. and A.L.J. designed research; A.S. and R.K.T. performed research; E.J.K., M.L.-P., and F.G. contributed unpublished reagents/analytic tools; A.S. and A.L.J. analyzed data; A.S. and A.L.J. wrote the paper.

This work was supported by NIH Grant R01 MH085726 (A.L.J.). The Ascl1 ${ }^{\text {CreeRT2 }}$ mice were created under a collaborative arrangement with the J. Johnson Laboratory (University of Texas Southwestern, Dallas, TX) and R. Reed Laboratory (Johns Hopkins University, Baltimore, MD). R. Reed and C. Leung provided the Ascl1 genomic DNA containing the homology arms, E.J.K. and J. Johnson generated the targeting construct, and A.L.J. and A.S. were responsible for targeting in ES cells and generating the targeted AsCl1 $7^{\text {CreeRT2 }}$ mouse line. We are grateful to $\mathrm{F}$. Berenshteyn and M. Bowers for help with mouse ES cell work, to D. Stephen for technical help, and to A. D. Garcia and E. Legue for insightful discussion and critical reading of this manuscript.

Correspondence should be addressed to Alexandra L. Joyner, Developmental Biology Program, Sloan-Kettering Institute, 1275 York Avenue, New York, NY 10021. E-mail: joynera@mskcc.org.

A. Sudarov's present address: Department of Neurology and Neuroscience, Weill Medical College of Cornell University, New York, NY 10021.

DOI:10.1523/JNEUROSCI.0479-11.2011

Copyright $\odot 2011$ the authors $\quad 0270-6474 / 11 / 3111055-15 \$ 15.00 / 0$
The cerebellum consists of a uniform layered cytoarchitecture organized into a complex set of folia. Embedded in the white matter (wm) are three pairs of cerebellar nuclei (cn) that consist of glutamatergic projection neurons and GABA-expressing interneurons. The cerebellum has an internal granule layer (igl) containing glutamatergic granule cells (gcs) and scattered interneurons. The adjacent monolayer consists of the cell bodies of GABAergic Purkinje cells (Pcs) and Bergmann glia (Bg). The outer molecular layer (ml) contains three types of interneurons (candelabrum, basket, and stellate) and gc axons and Pc dendrites. A critical question is whether there is a relationship between the timing of production of each cell type and its final organization within the microcircuitry.

The cerebellum has two spatially distinct germinal zones: the ventricular zone (vz) and the upper rhombic lip (url). A GIFM study using a url-specific Atoh1-CreER transgene demonstrated that glutamatergic neurons of the $\mathrm{cn}$ are generated before gc precursors (gcps) (Machold and Fishell, 2005). Cumulative fate mapping of the vz using a Ptfla $a^{\text {Cre }}$ allele identified Pcs, three of the interneuron types (Golgi, stellate, basket), and possibly astrocytes (Hoshino et al., 2005; Pascual et al., 2007) as arising from the vz. Recent bromodeoxyuridine (BrdU) birth-dating experiments in rodents indicated that GABAergic cerebellar interneurons are generated in an inside-to-outside progression (Leto et al., 2009). While unipolar brush cells in the igl are thought to arise from the url (Englund et al., 2006), the origin of Lugaro and candelabrum cells remains unknown. However, the full details of the temporal sequence of production and subsequent settling patterns of all vz-derived cells have not been determined. 
We reasoned that the Ascll gene could provide a tool for genetically birth dating cerebellar vz cells and studying the genetic regulation of cerebellum development, since Ascl1 is expressed in many neural progenitors as they transition from proliferation to differentiation (Guillemot et al., 1993; Battiste et al., 2007; Kim et al., 2007). In addition, Ascl1 is required to generate a normal number of Pax $2+$ interneurons and oligodendrocyte precursors in the cerebellum, at least at birth when null mutants die (Grimaldi et al., 2009). By combining GIFM with an Ascll ${ }^{\text {CreER }}$ allele and cerebellum-specific conditional deletion of Ascll, we discovered Ascl1 has diverse roles in generation of all vz-derived cell types, and propose a model for construction of cerebellar microcircuitry.

\section{Materials and Methods}

Mouse lines. The following mouse lines were used and genotyped as described previously: Ptfla Cre (Kawaguchi et al., 2002), Ascl1 ${ }^{\mathrm{CreER}}$ (Kim et al., 2011), Ascl fllx (Pacary et al., 2011), Rosa26 loxP-STOP-lacZ (Soriano, 1999), Rosa26 ${ }^{\text {loxP-STOP-YFP (Srinivas et al., 2001), and En1 }}{ }^{\text {Cre }}$ (Kimmel et al., 2000). Animals were maintained on a $12 \mathrm{~h}$ light/dark cycle and allowed ad libitum access to food and water. All animal studies were performed on an outbred SW background, under an approved Institutional Animal Care and Use Committee animal protocol according to the institutional guidelines at Memorial Sloan-Kettering Cancer Center. The day that a plug was detected was designated as embryonic day 0.5 (E0.5). The day of birth was designated as postnatal day 0 (P0). Adults were designated as P21 or older.

Fate mapping. Double heterozygous males $\left(A s c l 1^{C r e E R} ; R^{\text {loxP-STOP-YFP }}\right.$ or Ascl1 ${ }^{\text {CreER }}$; R26 ${ }^{\text {loxP-STOP-lacZ) }}$ were bred with SW females (5-6 weeks of age; Taconic Farms) to generate double heterozygous embryos. The R26 alleles were genotyped as previously described (Soriano, 1999). Tamoxifen (Tm) (T-5648; Sigma-Aldrich) was dissolved in corn oil (SigmaAldrich; C-8267) at a final concentration of $20 \mathrm{mg} / \mathrm{ml}$. The females were given $\mathrm{Tm}$ via gavage with animal feeding needles (Fine Science Tools) at noon on the designated days ( $2 \mathrm{mg}$ per $40 \mathrm{~g}$ of body weight). Dissected brains were immersion fixed for $20 \mathrm{~min}$ in $4 \%$ paraformaldehyde (PFA) at $4^{\circ} \mathrm{C}$, and then cryoprotected in 15 and $30 \%$ sucrose. The equilibrated samples were embedded in OCT (Tissue-Tek) using liquid $\mathrm{N}_{2}$-chilled 2 -methyl butane (Sigma-Aldrich). Frozen sections were obtained at a thickness of $20 \mu \mathrm{m}$. For whole-mount $\beta$-galactosidase ( $\beta$ gal) analysis, the samples were washed twice for $10 \mathrm{~min}$ at room temperature in Xgal buffer $\left(0.05 \%\right.$ deoxycholate, $1 \mathrm{~mm} \mathrm{MgCl}_{2}, 0.02 \% \mathrm{NP} 40$ in PBS, pH 7.4) and then placed in Xgal reaction buffer $(1 \mathrm{mg} / \mathrm{ml} \mathrm{Xgal,} 5 \mathrm{~mm}$ potassium ferrocyanide, $5 \mathrm{~mm}$ potassium ferricyanide) at $37^{\circ} \mathrm{C}$ overnight. The extent of the marked domain was the same for embryos and postnatal mice within a litter $(n>5)$ and between litters $(n>4)$, although the percentage of labeled cells varied a small amount between animals. Sections were fixed for $5 \mathrm{~min}$ in 4\% PFA/PBS (room temp), washed twice in Xgal wash buffer for $10 \mathrm{~min}$ each, and then stained overnight in Xgal reaction buffer at $37^{\circ} \mathrm{C}$. Sections were counterstained with $0.005 \%$ Nuclear Fast Red. Ptfla-Ascl1 conditional knock-out (cko) and En1-Ascl1 cko animals were given an intraperitoneal injection of sodium pentobarbital and transcardially perfused with $20-30 \mathrm{ml}$ of PBS followed by $60 \mathrm{ml}$ of $4 \%$ paraformaldehyde. Brains were dissected and cryoprotected in $30 \%$ sucrose until sectioning. Tissue was sectioned on a cryostat at $40 \mu \mathrm{m}$ and serial free-floating sections were collected in 96 -well plates containing $0.05 \%$ sodium azide, and then stored at $4^{\circ} \mathrm{C}$ until use.

RNA in situ hybridization, histology, and immunofluorescent immunohistochemistry. Section RNA in situ analysis was performed as described previously (Li and Joyner, 2001). Ascl1 (Guillemot and Joyner, 1993) and Cre (Machold and Fishell, 2005) probes were prepared as described previously. Immunohistochemistry using immunofluorescence was performed using standard staining procedures with the following antibodies: mouse anti-BrdU (BD Biosciences), mouse anticalbindin (Swant), rabbit anti-GABA (Sigma-Aldrich), rat anti-GFP (Nacalai Tesque), rabbit anti-GFP (Invitrogen), rabbit anti- $\beta$ gal (Biogenesis), chicken anti- $\beta$ gal (Abcam), rabbit anti-Pax6 (Millipore Biosci- ence Research Reagents), rabbit anti-Pax2 (Abcam), mouse anti-Ki67 (BD Biosciences), guinea pig anti-Ascll (gift from J. Johnson, University of Texas Southwestern, Dallas, TX), mouse anti-parvalbumin (Abcam), rabbit anti-neurogranin (Abcam), mouse anti-GFAP (Abcam), sheep anti-CAII (Serotec), and mouse anti-S100 $\beta$ (Abcam). Sections were mounted in Vectashield with DAPI (Vector Laboratories) and examined with a fluorescent microscope (Axio Observer; Zeiss). Fluorescent images were captured as $1.5 \mu \mathrm{m}$ optical sections using Zeiss Observer software for Apotome and processed using Adobe Photoshop. Orthogonal analysis was performed to confirm coexpression of two markers. For BrdU staining, sections were pretreated for antigen retrieval by steaming in sodium citrate for $15 \mathrm{~min}$. For bright-field staining, species-specific, biotinylated secondary antibodies (Vector) were used at 1:400 dilution followed by incubation in $\mathrm{ABC}$ (avidin-biotin complex) (Vector). Visualization was achieved using diaminobenzidine (Vector) as the developing agent.

BrdU staining and quantification. BrdU (Sigma-Aldrich; B9285) was dissolved in $0.007 \mathrm{~N} \mathrm{NaOH}$ and administered by intraperitoneal injection. To determine proliferative status of cells in the cerebellum, pregnant females were injected intraperitoneally with $100 \mu \mathrm{g}$ of BrdU per gram of body weight $1 \mathrm{~h}$ before killing. To assay the birth date of cells, pregnant females were injected intraperitoneally with $100 \mu \mathrm{g}$ of BrdU per gram of body weight $12 \mathrm{~h}$ before Tm administration and were killed at $\mathrm{P} 21$. For early postnatal stages, pups were injected with BrdU $12 \mathrm{~h}$ before Tm intracutaneous injection. To quantify the number of BrdU+ Ascl1 ${ }^{\text {CreER }}$ GIFM-marked cells at P21, the percentage of BrdU + cells was calculated by counting the total number of fate-mapped cells $(\beta \mathrm{gal}+$ cells) on at least six sections per cerebellum of at least three animals. Measurements of cells from multiple embryos/animals were pooled into datasets.

Quantification of anterior-posterior distribution of Pcs. To count the percentage of Pcs per cardinal lobe, E18.5 Xgal-stained sections of Ascl1 ${ }^{\text {CreER }}$ GIFM animals that received Tm at E11.5 or E12.5 were analyzed at the midline, and 100 and $200 \mu \mathrm{m}$ off the midline. For Figure $3 G$, we used one colored dot for every three to five Xgal+ Pcs to schematize the average distribution of marked Pcs.

Quantification of Ascl1 CreER GIFM-marked cells. To determine the temporal patterns of $\mathrm{Ascl}^{\mathrm{CreER}}$-marked cells, we analyzed GFPneurogranin, GFP-parvalbumin, GFP-CAII, and GFP-GFAP doubleimmunostained P21 cerebella of $\mathrm{Ascll}^{\mathrm{CreER/+}} ; \mathrm{R}^{\mathrm{loxP}-\mathrm{STOP}-\mathrm{YFP} /+}$ mice that received Tm at E13.5, E14.5, E17.5, P0, P1, P4, and P7. At least four to six serial sections per GIFM mouse were analyzed to determine the percentage of each cell type marked at each Tm administration time point. In addition to distinct cell type-specific markers, we also examined the morphology and layer position to determine the cell type.

Quantification of Ptfla-Ascl1 cko and En1-Ascll cko phenotype. For all different measurements we analyzed at least four to six sections from at least three animals per genotype. To quantify the number of Pcs, the number of Pc bodies was counted per length of Pc layer on sections immunostained for anti-calbindin. To assess the number of basket and stellate interneurons in the $\mathrm{ml}$, the $\mathrm{ml}$ of hematoxylin and eosin-stained sections was divided along the middle to produce lower and upper sublayers and the number of positive cells was counted within each sublayer, respectively. To quantify the number of Golgi interneurons, oligodendrocytes, and astrocytes, cells double positive for GFP and neurogranin, CAII, or $\mathrm{S} 100 \beta$, respectively, were counted on at least six serial sections from at least three animals per genotype. The average number of each cell type per square millimeter was determined and the mutant numbers were normalized to controls, which were set as 1 . To quantify the cerebellum circumference, the ImageJ (http://rsb.info.nih.gov/ij/) tracing tool was used to outline the outer surface of the cerebellum on at least six sections evenly spaced along the medial-lateral (M-L) axis per animal and the length measured. The average length in millimeters was determined and the mutant numbers were normalized to controls, which were set as 1 .

Quantification of fate-mapped gcps within the external granule layer of Ptfla ${ }^{\mathrm{Cre} /+} ; \mathrm{Ascl}^{-/-}$. Sections of wild-type and mutant littermate controls were processed and stained for Xgal simultaneously. The number of gcps was counted within a $100 \mu \mathrm{m}$ length of the external granule layer (egl) at the top of the three cardinal lobes depicted in Figure 8,E and $F$. 


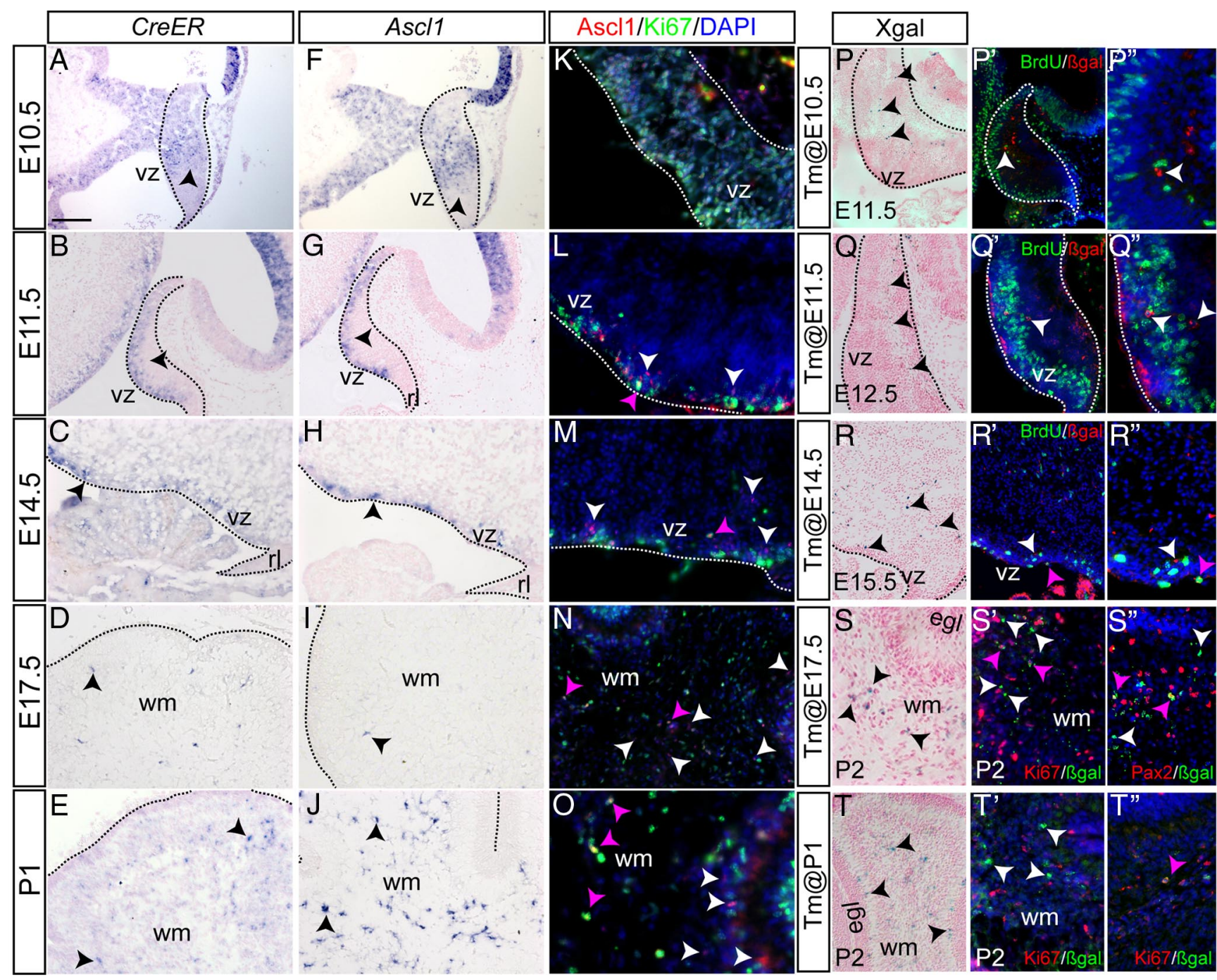

Figure 1. The $A s c 1^{\text {CreER }}$ allele is expressed similar to $A s c 11$ and primarily marks cells that rapidly stop dividing. (reER expression $(\boldsymbol{A}-\boldsymbol{E})$ closely resembles endogenous $A s c / 1$ expression $(\boldsymbol{F}-\boldsymbol{J})$ in the cerebellum (outline) throughout embryogenesis. $\mathbf{K}-\mathbf{0}$, Ascl1-expressing cells have distinct proliferative characteristics at various time points. $\boldsymbol{P}-\boldsymbol{T}^{\prime \prime}, A s \mathrm{As} 7^{\mathrm{CreER/+}} ; R 262 \mathrm{R}^{\mathrm{IacZ} /+}$ animals were given Tm at different time points and killed $24 \mathrm{~h}$ later. One hour BrdU pulse was given to $A s c 11^{\mathrm{CreER} /+} ; R 262 \mathrm{R}^{\mathrm{lacZ} /+}$ animals before killing. $\boldsymbol{P}$, Tm was administered at E10.5, and sagittal sections of E11.5 embryos were analyzed by Xgal staining. Xgal + cells were found away from the vz. $\boldsymbol{P}^{\prime}$, Double-labeling immunohistochemistry for BrdU and $\beta$ gal shows BrdU (green) in the vz, whereas Ascl ${ }^{\text {(reeR }}$

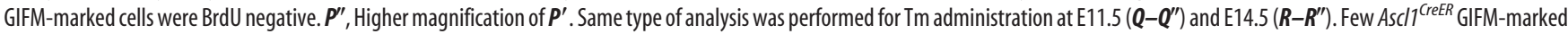
cells incorporated BrdU (pink arrows) when Tm was administered at E14.5 $\left(\boldsymbol{R}^{\prime}, \boldsymbol{R}^{\prime \prime}\right) . \boldsymbol{S}^{\prime}$, When Tm was administered at E17.5 and the cerebellum analyzed at P2, few cells were Ki67+ (pink arrows). $S^{\prime \prime}$, The majority of $\beta \mathrm{gal}+$ cells were Pax2 + (pink arrowheads). $\boldsymbol{T}^{\prime}, \boldsymbol{T}^{\prime \prime}$, When Tm was administered at P1, very few of the fate-mapped cells were Ki67+ (pink arrow). rl, Rhombic lip. Scale bar: $A-P^{\prime}, \mathbf{Q}, \mathbf{Q}^{\prime}, \mathbf{S}-\boldsymbol{T}^{\prime \prime}, 50 \mu \mathrm{m} ; \boldsymbol{P}^{\prime \prime}, \mathbf{Q}^{\prime \prime}, \boldsymbol{R}^{\prime \prime}, 30 \mu \mathrm{m}$.

\section{Results}

Ascl1 ${ }^{\text {CreER }}$ expression is similar to endogenous Ascl1 in the cerebellum vz during embryogenesis

As a possible means to genetically mark and birth date cells as they leave the cerebellum vz, we engineered an $A s c l{ }^{\text {CreER }}$ knock-in allele using gene targeting to replace the coding sequences of $A s c l 1$ with $\mathrm{CreER}^{T 2}$ (Kim et al., 2011). In subsequent GIFM studies, temporal control of cell marking was obtained by administering $\mathrm{Tm}$ at specific time points during development to activate $\mathrm{CreER}^{\mathrm{T} 2}$. To highlight the morphology of marked cells, two reporter alleles, R26 $6^{\text {loxP-STOP-lacZ }}$ (Soriano, 1999) and R26 $6^{\text {loxP-STOP-YFP (Srinivas et al., }}$ 2001), were used. We refer to double heterozygous mice $A s c l 1^{\mathrm{CreER} /{ }^{+}}$; $R 26^{\text {loxP-STOP-lacZ/+ }}$ or Ascl1 ${ }_{\text {CreER/+ }} ; R_{2} 6^{\text {loxP-STOP-YFP/+ }}$ as Ascl ${ }^{\text {CreER }}$ GIFM mice. Many cells expressing Ascl1 ${ }^{\text {CreER }}$ should undergo Cre-mediated excision of the loxP flanked STOP cassette $\sim 6-36$ $\mathrm{h}$ after administration of Tm, resulting in permanent and heritable $\beta$ gal or YFP expression (Joyner and Zervas, 2006). By activat- ing the $\mathrm{CreER}^{\mathrm{T} 2}$ protein at different embryonic and early postnatal stages, distinct cohorts of Ascl1-expressing cells were labeled and their subsequent fates determined during development or in the adult mouse cerebellum (see details below).

We verified that the $A s c l 1{ }^{\mathrm{CreER}}$ knock-in allele is expressed like Ascl 1 in the cerebellum by comparing CreER and Ascl 1 mRNA expression on adjacent sections of $\mathrm{Ascll}^{\mathrm{CreER} /+}$ embryos and postnatal mice using RNA in situ hybridization analysis (Fig. $1 A-J$ ) (Zordan et al., 2008). Indeed, we observed a similar expression pattern of CreER and Ascl1 at all stages. At E10.5, Ascl1 and $C r e E R$ were detected near the vz, but restricted to the lateral cerebellum primordium (Fig. $1 A, F$ ). By E11.5, both transcripts were found near the vz throughout the M-L axis, except near the midline (Fig. $1 B, G$ ). At E12.5-E14.5 (Fig. 1C,H) (data not shown), Ascl1 and CreER were detected in the vz region throughout the M-L axis. In contrast, at E17.5 only a few Ascl1- and CreER-expressing cells were found near the vz, and instead cells 
in the cerebellar wm expressed both transcripts (Fig. 1D,I, arrows). At P0 and later, Ascll was only detected in the wm (Fig. $1 E, J)$ (data not shown). In conclusion, $A s c l 1^{\text {CreER }}$ is expressed similar to Ascl1 from at least E10.5 to P5 and is initially restricted to cells near the vz and then becomes expressed in the wm where glial and interneuron progenitors reside.

\section{The earliest $A s c l 1^{\mathrm{CreER}}$-marked cells are GABAergic interneurons of the cn and Pcs}

In many regions of the embryonic CNS and PNS, studies have indicated that $A s c l 1$ is a proneural gene. For example, overexpression of Ascll in the chick neural tube induces progenitors to rapidly exit the cell cycle and leave the vz (Nakada et al., 2004), whereas loss of Ascl1 results in a delay of neuronal differentiation in the spinal cord and telencephalon (Guillemot et al., 1993; Casarosa et al., 1999; Parras et al., 2004; Helms et al., 2005; Pattyn et al., 2006; Wildner et al., 2006). Furthermore, GIFM studies in the spinal cord using an Ascl1-CreER bacterial artificial chromosome (BAC) found that the initial population of marked cells was outside the mantle zone (Battiste et al., 2007). In the cerebellum, however, the transgene was found to mark only a limited number of vz-derived cell types, specifically Pcs only on the last of the three days when they are born (Tm administration at E12.5), cn interneurons at two stages (E10.5 and E14.5) rather than only the one day they are born (Altman and Bayer, 1997), and oligodendrocytes only at a late embryonic stage (E17.5) (Kim et al., 2008). Additionally, no GABAergic interneurons in the igl or $\mathrm{ml}$ were labeled using the Ascl1-CreER BAC transgenic line (Kim et al., 2008). Thus, either Ascl1 is not expressed in all cells as they leave the cerebellar vz, or the BAC transgene does not faithfully recapitulate Ascll expression.

Given the extensive expression of CreER in the vz and wm of $A s c l 1^{\text {CreER }}$ mice, we used GIFM to test whether the Ascl1 ${ }^{\text {CreER }}$ allele can be used to mark all vz-derived cell types in the cerebellum, and whether marking occurs near the time when they exit the cell cycle. We began by administering $\mathrm{Tm}$ at embryonic stages when Pcs and cn interneurons are born (E11-E13). Consistent with traditional ${ }^{3} \mathrm{H}$ thymidine birth dating experiments (Altman and Bayer, 1997), we found that when Tm was administered at E10.5 only Pcs and GABAergic cells of the cn were marked, as confirmed by double immunohistochemistry (IHC) for $\beta$ gal and GABA or the Pc-specific marker calbindin (Fig. 2B,C). In addition, when Tm was administered at E11.5 or E12.5, only Pcs were marked with Ascl1 ${ }^{\text {CreER }}$ GIFM (Fig. 2D,E). Furthermore, no GABAergic interneurons were found in the igl or $\mathrm{ml}$ (cerebellar cortex) at all three time points. Thus, the first cell types to express Ascll and be generated by the vz are the GABAergic interneurons of the cn and Pcs in the cortex, both of which project to the excitatory neurons of the $\mathrm{cn}$ that are derived from the url around the same time.

\section{During E10.5-E12.5, Ascl1 ${ }^{\text {CreER }}$ GIFM marks cerebellar ventricular zone-derived cells around the time they become postmitotic}

Given the correlation between the cell types marked with Ascl1 ${ }^{\text {CreER }}$ GIFM between E10.5 and E12.5 and previous birthdating experiments showing that these cells are born during this time period, we tested whether cells express $A s c l{ }^{\text {CreER }}$ around the time of their final cell division. IHC analysis of Ascll protein and Ki67 (proliferation marker) at E10.5 detected Ascl1 in many dividing cells throughout the cerebellar vz (Fig. $1 \mathrm{~K}$ ). In contrast, at E11.5 and E12.5 only rare Ascl1+ cells expressed Ki67 (Fig. $1 L$ ) (data not shown). We next analyzed the initial populations of

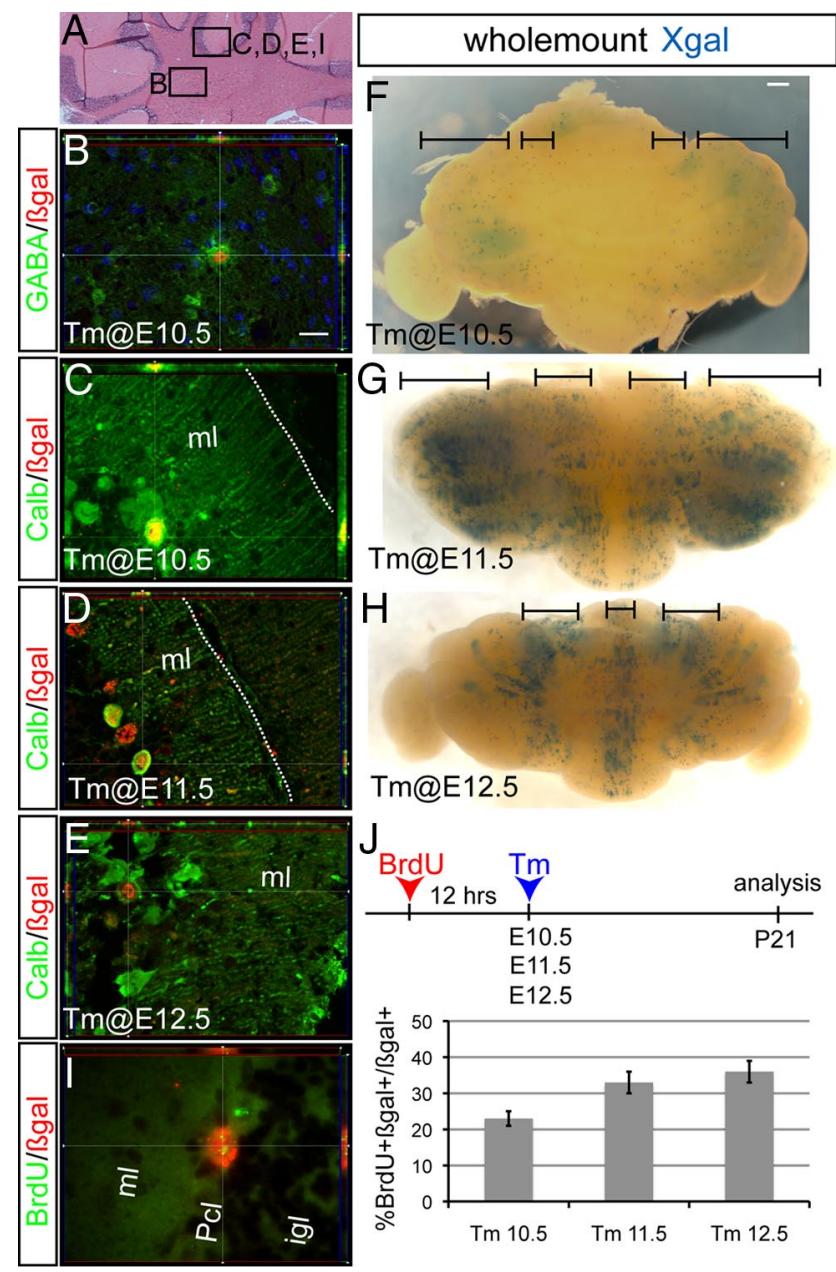

Figure 2. GABAergic cn interneurons and Purkinje cells are the first cell types marked by As $17^{\text {CreeR }}$ GIFM. A, Coronal section of the adult cerebellum highlighting where images in $\boldsymbol{B}-\boldsymbol{E}$ and $\boldsymbol{I}$ were taken. $\boldsymbol{B}$, Double-labeling immunohistochemistry for GABA (green) and $\beta \mathrm{gal}$ (red) shows that cn interneurons were marked when Tm was administered at E10.5. Anti-calbindin (green) and anti- $\beta$ gal (red) double-labeling immunohistochemistry shows that fate-mapped cells are Purkinje cells when Tm was administered at E10.5 (C), E11.5 (D), and E12.5 (E). F-H, Dorsal views of whole-mount Xgal staining of P21 cerebella when Tm was administered at E10.5 $(\boldsymbol{F}), \mathrm{E} 11.5(\boldsymbol{G})$, and E12.5 $(\boldsymbol{H}) . \boldsymbol{I}$, BrdU was administered $12 \mathrm{~h}$ before $\mathrm{Tm}$ administration at E10.5, E11.5, or E12.5 and analysis performed at P21. Double-labeling immunohistochemistry for $\beta$ gal (red) and BrdU (green) shows that Ascl1 $7^{\text {CreeR }}$ GIFM-marked Pcs retained BrdU labeling. $J$, Quantification of the number of double-positive BrdU and $\beta$ gal Pcs (mean \pm SEM; $n=3$; unpaired $t$ test). Pcl, Purkinje cell layer. Scale bar: $\boldsymbol{A}, 100 \mu \mathrm{m} ; \boldsymbol{B}-\boldsymbol{E}, \boldsymbol{I}, 20 \mu \mathrm{m} ; \boldsymbol{F}-\boldsymbol{H}, 600 \mu \mathrm{m}$.

cells marked with $A s c l 1^{\text {CreER }}$ GIFM $24 \mathrm{~h}$ after Tm administration (Fig. $\left.1 P-T^{\prime \prime}\right)$. When Tm was administered on each day between E10.5 and E12.5, the initial populations of marked cells ( $\beta \mathrm{gal}+$ ) within the cerebellar primordium appeared to be beside the vz (Fig. $\left.1 P-P^{\prime \prime}, Q-Q^{\prime \prime}\right)$. To determine whether any of the initial population of Ascl ${ }^{\text {CreER }}$ GIFM-marked cells were mitotically active, a single dose of $\mathrm{BrdU}$ was administered $1 \mathrm{~h}$ before killing the mice $24 \mathrm{~h}$ after administering Tm. Strikingly, none of the $\beta \mathrm{gal}+$ cells were BrdU+. Thus, cells marked using Ascl ${ }^{\text {CreER }}$ GIFM by administration of tamoxifen at E10.5, E11.5, or E12.5 continue to divide for $<24 \mathrm{~h}$ (Fig. $\left.1 P^{\prime}, P^{\prime \prime}, Q^{\prime}, Q^{\prime \prime}\right)$. To investigate whether Ascl1 ${ }^{\text {CreER }}$ GIFM marks cells close to the time of their final cell division throughout E10.5-E12.5, we administered BrdU $12 \mathrm{~h}$ before administering Tm and colabeled marked cells for $\beta$ gal and BrdU at P21. Indeed, we found that many fate-mapped cells marked using $A s c l{ }^{\text {CreER }}$ GIFM at all three stages retained BrdU labeling $(\sim 22-35 \%)$ and thus underwent their final cell division 


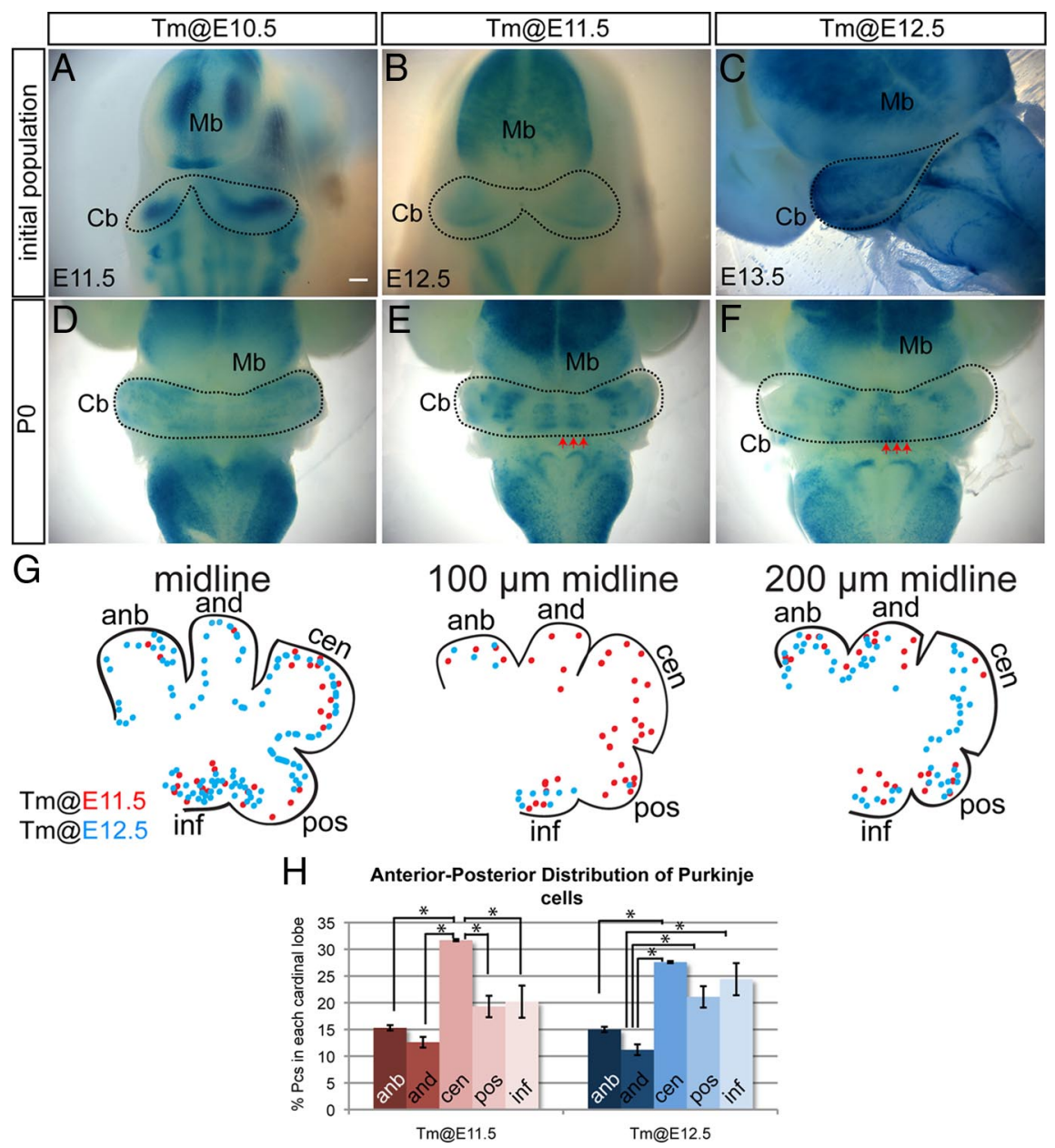

Figure 3. Purkinje cells marked with $A s C{ }^{\text {CreeR }}$ GIFM on consecutive days settle in distinct M-L and A-P patterns. A-C, Wholemount $X$ gal staining of embryos $24 \mathrm{~h}$ after Tm administration. $A$, E11.5 whole-mount Xgal staining of Pcs marked at E10.5 reveals that Pcs were uniformly labeled in the lateral cerebellar primordium. $\boldsymbol{B}$, At E12.5, whole-mount Xgal staining of Pcs marked at E11.5 shows labeling of Pcs in the cerebellar primordium excluding the midline. C, E13.5 whole-mount Xgal staining of Pcs marked at E12.5 reveals that Pcs were uniformly labeled throughout the M-L axis of the cerebellum.D, PO whole-mount Xgal staining of Pcs marked at E10.5 shows that Pcs were found throughout the cerebellum except the midline. E, PO whole-mount Xgal staining of Pcs marked at $E 11.5$ depicts four pairs of distinct M-L Pc bands. $F, P O$ whole-mount Xgal staining of Pcs marked at E12.5 shows a single midline Pc band and two bilateral clusters in the paravermis. G, Summary schematic of A-P distribution pattern of Pcs marked at E11.5 (red) and E12.5 (blue). The arrows in $\boldsymbol{E}$ and $\boldsymbol{F}$ indicate positions analyzed in $\boldsymbol{G}$. $\boldsymbol{H}$, The percentage of marked Pcs residing in each of the cardinal lobes at E18.5 cerebellum. Error bars indicate SEM. Mb, Midbrain; Cb, cerebellum; anb, anterobasal; and, anterodorsal; cen, central; pos, posterior; inf, inferior. Scale bar: A-C, $200 \mu \mathrm{m} ; \mathbf{D}-\boldsymbol{F}, 350 \mu \mathrm{m} .{ }^{*} p<0.05$.

around the time of genetic marking (Fig. $2 I, J$ ). Our finding that many cells labeled with BrdU at E10 and marked with Ascl1 ${ }^{\text {CreER }}$ GIFM by Tm administration at E10.5 are BrdU/ $\beta$ gal + at P21 suggests that many of the BrdU+/Ascl1 + cells detected at E10.5 must be undergoing their final (or second-to-last) cell division. In summary, during at least E10.5-E12.5, Ascl1 ${ }^{\mathrm{CrER}}$ GIFM can be used to construct a temporal birth date map of vz-derived cells in the cerebellum. Furthermore, the resolution provided by genetic marking allows for the characterization of the marked cells at a level unattainable with BrdU.

\section{Purkinje cells born on different days settle in distinct positions along two axes}

Previous studies suggested that cohorts of Pcs born on each day between E10.5 and E12.5 settle in distinct M-L or anterior-posterior (A-P) positions (Altman and Bayer, 1997; Hashimoto and Mikoshiba, 2003). Since Ascl1 is expressed homogenously in the lateral cerebellum $\mathrm{vz}$ and progressively expands into the midline, we were curious to determine whether Ascl1-expressing progenitors give rise to the predicted spatially distinct Pc populations on different days. Strikingly, wholemount staining of the cerebella of adult Ascl1 ${ }^{\text {CreER }}$ GIFM mice with Xgal revealed a distinct M-L organization of the Pcs marked on each day (Fig. $2 \mathrm{~F}-H$ ). The earliest marked Pcs (Tm at E10.5) not only predominantly settled in the lateral cerebellum (hemispheres) but also in addition formed one pair of bilateral thin stripes at the junction between the vermis and hemispheres (paravermis) (Fig. 2F). In contrast, the Pcs marked with Tm at E11.5 settled in four bilateral pairs of broad stripes, with a mostly negative stripe in the midline (Fig. 2G). Surprisingly, the latest marked Pcs at E12.5 settled in a single stripe in the midline and in a pair of bilateral stripes in the paravermis, despite Ascl1 ${ }^{\text {CreER }}$ expression throughout the M-L axis (Fig. $2 \mathrm{H}$ ). These findings provide further evidence that $A s c l 1^{C r e E R}$ is expressed in all Pcs around the time they are born, since the stripe patterns are similar to those reported by marking Pcs with a replication-defective adenoviral vectors thought to infect cells in their last cell division on E10.5, E11.5, and E12.5 (Hashimoto and Mikoshiba, 2003).

Given the distinct M-L organization of Pcs observed in the adult cerebellum, we next tested whether Pcs are organized in the same M-L organization when they first leave the vz by analyzing the distribution of Pcs marked by Ascl1 ${ }^{\text {CreER }}$ GIFM $24 \mathrm{~h}$ after $\mathrm{Tm}$ administration in wholemount brains (Fig. 3). Strikingly, unlike the pattern of labeling in the adult, we found that the initial marked populations of Pcs were not in stripes as previously reported (Hashimoto and Mikoshiba, 2003) but instead were distributed similar to the endogenous Ascl1 RNA expression. Specifically, Pcs marked with Ascl1 ${ }^{\text {CreER }}$ GIFM at E10.5 were observed uniformly across the lateral E11.5 cerebellum (Fig. 3A), whereas labeling at E11.5 resulted in uniform marking everywhere but the midline (Fig. 3B). Similarly, when Tm was administered at E12.5, the initial marked population of Pcs was found throughout the M-L axis, although very few vz-derived cells are present at the midline at E13.5 (Fig. 3C). Interestingly, when cerebella of Ascl1 ${ }^{\text {CreER }}$ GIFM mice were marked with Tm on each day between E10.5 and E12.5 and stained with Xgal in whole mount at P0, the Pcs were organized in distinct M-L stripes similar to those in the adult (Fig. 3D-F). Thus, Pcs are born uniformly within the vz, but then settle into parasaggital stripes by late embryogenesis.

We next examined the A-P distribution pattern of Pcs marked with Tm on E11.5 and E12.5 at E18.5, after the M-L stripes of Pcs born on different days are established. Since the vast majority of Pcs labeled with Tm administration on E10.5 settle laterally, we did not analyze such fate-mapped cells. When the sum of the 
distribution of Pcs in three sagittal sections (midline, $\sim 100$ and $\sim 200 \mu \mathrm{m}$ from the midline) was determined, we found no striking spatial pattern in settling of Pcs, although the central lobe, which is the largest lobe, contained a significantly higher percentage of total labeled Pcs compared with the other lobes (Fig. $3 G, H)$. If the size of each lobe were taken into account, then the inferior lobe would have contained the highest proportion of marked cells. Interestingly, when we examined the A-P distribution of Pcs at each of the three separate M-L positions, we found distinct settling patterns for each position and day of marking. In the most midline sections, we found that the few of Pcs marked at E11.5 primarily occupied the central and inferior lobes, whereas Pcs marked a day later were spread throughout the A-P axis with the highest proportion in the inferior lobe. In sections $\sim 100 \mu \mathrm{m}$ away from the midline, Pcs marked with Tm at E11.5 settled throughout the A-P axis, whereas Pcs marked a day later primarily occupied the most anterior lobes (anterobasal) and the inferior lobe. Last, in the area $\sim 200 \mu \mathrm{m}$ away from the midline, Pcs marked at E11.5 preferentially settled in all lobes but the central lobe, whereas Pcs marked at E12.5 settled throughout the A-P axis. A $\left[{ }^{3} \mathrm{H}\right]$ thymidine labeling study of Pcs done in rat suggested that, in the medial vermis, the earliest born Pcs occupy the central lobe, and the next born Pcs settle in the posterior lobe followed by the inferior lobe, with the latest born Pcs occupying the anterodorsal then anterobasal lobe (Altman and Bayer, 1997). There are both similarities and differences if our Pc genetic birthdating study is compared with the previous $\left[{ }^{3} \mathrm{H}\right]$ thymidine study. The most likely explanation for the differences is that we analyzed the A-P settling patterns in three different areas of the vermis, whereas the previous study described the A-P pattern only near the midline region.

\section{Cerebellar inhibitory interneurons express Ascl1 in distinct temporal patterns starting at E13.5}

Given the exclusivity in marking of vz-derived Pcs and cn neurons with $A s c l 1{ }^{C r e E R}$ GIFM at E10.5-E12.5, we next asked whether other GABAergic neurons of the cerebellar cortex are marked with $A s c l 1^{\text {CreER }}$ GIFM after E12.5. Each of the four GABAergic interneuron subtypes can be distinguished based on their morphology and their distinct position in the cortex (Altman and Bayer, 1997). Basket cells located in the inner molecular layer (Fig. 4A, $A^{\prime}$ ), and stellate cells located in the outer molecular layer (Fig. $4 B, B^{\prime}$ ), synapse with Pc soma and dendrites, respectively, and express parvalbumin (Celio, 1990; Bastianelli, 2003). Neurogranin-expressing Golgi cells have large soma within the glomeruli of the igl where they synapse with gcs, and receive inputs from both gc parallel fibers in the molecular layer and mossy fiber axon terminals (Fig. $4 C, C^{\prime}$ ). Basket and stellate cells sharpen the response of Pcs to activity from the parallel fibers, whereas the Golgi cells limit the duration of gc activation by mossy fibers (Altman and Bayer, 1997; Barmack and Yakhnitsa, 2008). Much less is known about the recently identified candelabrum interneurons that have small cell bodies in the Pc layer and extensive chandelier-like processes in the molecular layer (Fig. 4D) (Lainé and Axelrad, 1994).

We found that, when Tm was administered at E13.5, E14.5, E17.5, P0, P1, P4, or P7, the majority of fate-mapped cells in P21 Ascl1 ${ }^{\text {CreER }}$ GIFM mice were interneurons in the cerebellar cortex. The remaining marked cells were glia (see details below). Strikingly, no Pcs or cn interneurons were marked at these stages of Tm administration. Furthermore, the relative proportion of each interneuron cell type that was marked changed as development progressed (Fig. $4 \mathrm{~K}$ ). When Tm was administered at E13.5, $\sim 50 \%$ of all the marked cells were Golgi cells (igl interneurons), whereas only $\sim 13$ and $\sim 16 \%$ were basket and stellate cells (molecular layer interneurons), respectively (Fig. $4 E, K$ ). When Tm was administered at E14.5, the majority of marked cells continued to be Golgi cells ( $\sim 49 \%$ ), but $\sim 25 \%$ of the fate-mapped $(\mathrm{YFP}+)$ cells were now basket cells and only $\sim 10 \%$ were stellate cells (Fig. $4 F, K$ ). In contrast, when Tm was administered at E17.5, only $\sim 14 \%$ of marked cells were Golgi cells, the majority were basket cells $(\sim 36 \%$ of all YFP + cells $)$, and $\sim 22 \%$ were stellate cells (Fig. $4 G, K$ ). Interestingly, $\sim 1 \%$ of YFP + cells were candelabrum interneurons at this stage of marking (Fig. $4 D, K$ ). When Tm was administered at P0, only one labeled Golgi cell was observed in three mice examined (Fig. $4 H, K)(n=36$ sections in 3 animals). The proportion of marked basket cells remained at $\sim 30 \%$, whereas the majority of all marked cells were stellate interneurons $(\sim 63 \%)$ with candelabrum cells at $\sim 2 \%$. When Tm was administered at $\mathrm{P} 1$, the majority of all marked cells continued to be stellate cells $(\sim 75 \%)$, basket cells were decreased to only $\sim 19 \%$, and candelabrum cells to only $\sim 0.2 \%$ (Fig. $4 I, K$ ). Finally, at P4 and P7, the only interneurons labeled were stellate cells ( $\sim 89 \%$ of all YFP + cells) (Fig. $4 J, K)$ (data not shown). Our finding that the four GABAergic interneuron subtypes express Ascl1 in a temporal sequence that correlates with their final inside-to-outside position is reminiscent of the pattern observed when three of the interneuron types were previously birth dated in rodents at more limited time points (Altman and Bayer, 1997; Leto et al., 2009). By extrapolation, our results indicate that candelabrum interneurons likely follow this same rule.

\section{Early-born cerebellar cortex inhibitory interneurons express} Ascll as they leave the cell cycle and ventricular zone

We next tested whether cerebellum interneurons, like Pcs, are marked with $A s c l 1^{C r e E R}$ GIFM when they are born. Interestingly, when BrdU was administered $12 \mathrm{~h}$ before administering Tm at E13.5, E14.5, P2, or P7, double IHC staining for BrdU and $\beta$ gal at $\mathrm{P} 21$ revealed that some stellate (Fig. $5 A, A^{\prime}$ ), basket (Fig. $5 B, B^{\prime}$ ), and Golgi (Fig. $5 C, C^{\prime}$ ) cells retained BrdU and thus were birth dated with $A s c l 1^{\text {CreER }}$ GIFM. Quantification of cells labeled when Tm was administered at E13.5 or E14.5 demonstrated that $\sim 25$ and $\sim 22 \%$, respectively, of Ascl1 ${ }^{\text {CreER }}$ GIFM-marked cerebellar interneurons retained BrdU. Furthermore, $\sim 45 \%$ of the BrdUand $\beta$ gal-labeled interneurons were Golgi cells (located in the igl) and the remainder were basket and stellate cells (found in the $\mathrm{ml}$ ). Therefore, all three interneuron types are born as early as E13, with an apparent preference for Golgi cells (Fig. 5D). In contrast to interneurons labeled at E13.5/E14.5, only $\sim 5$ and $\sim 12 \%$ of interneurons labeled by Tm administration on P2 and P7 were double positive for BrdU and $\beta$ gal, respectively. It is possible that the lower percentage of BrdU-labeled interneurons after birth compared with midembryonic stages is a result of the different Tm administration techniques. For embryonic stages, mothers were administered Tm by oral gavage, whereas postnatal pups received Tm via subcutaneous injection which results in faster (6-12 h) activation of Cre (Nguyen et al., 2009). The latter route of administration would therefore result in the active form of Tm reaching the cerebellum closer to the time of Tm administration, and thus closer to the time of BrdU incorporation (within 18-24 $\mathrm{h}$ rather than 24-30 h). If Ascl1 expression is initiated later than $18 \mathrm{~h}$ after DNA synthesis, then the active form of Tm would be available for only a subset of the time when Ascl1 is expressed.

We next examined whether Ascl1 is expressed in proliferating precursors after E13.5. IHC showed that, at E14.5, E17.5, and P1, few Ascl1+ cells were Ki67+ (proliferating) (Fig. 1M-O, pink 


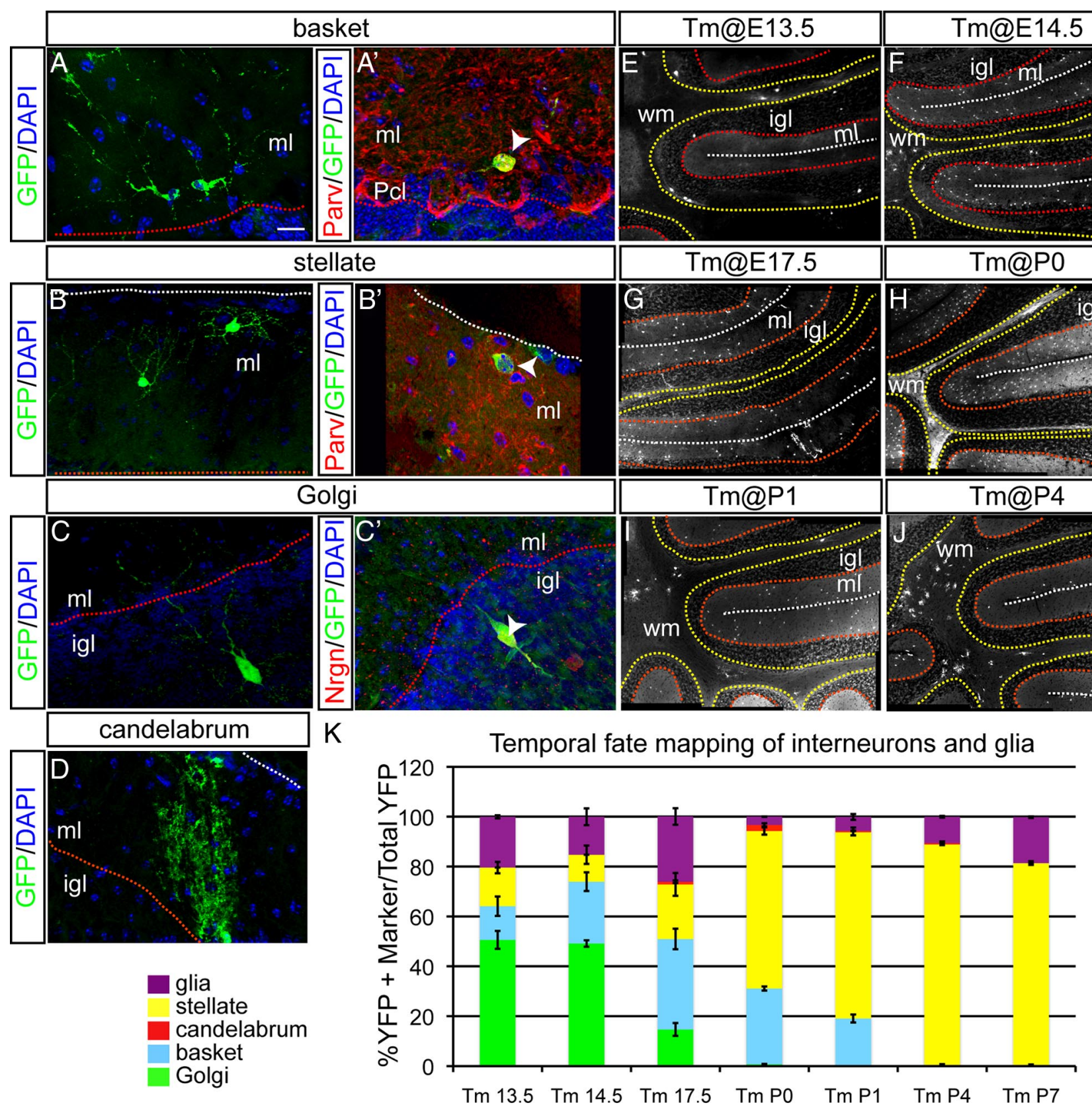

Figure 4. Temporal fate mapping of cerebellar interneurons reveals inside-to-outside settling in the cortex. All sections were analyzed at P21. $A-C$, An example of fate-mapped cell types when Tm was administered at E14.5. $A, A^{\prime}$, Distinct morphology of basket cells, found in the $\mathrm{ml}$ close to Pcl, is shown. Double-labeling immunohistochemistry for parvalbumin (red) and YFP (green) identifies some fate-mapped cells in inner $\mathrm{ml}$ as basket cells. $\boldsymbol{B}, \boldsymbol{B}^{\prime}$, Distinct morphology of stellate cells located in the outer $\mathrm{ml}$ is shown. Double-labeling immunohistochemistry for parvalbumin (red) and YFP (green) in the outer ml identifies some fate-mapped cells as stellate cells. $C, C^{\prime}$, Large size of fate-mapped interneurons in the igl indicates Golgi cells. Double-labeling immunohistochemistry for neurogranin (red) and YFP ( green) confirms Golgi cell identity. D, A chandelier-shaped candelabrum fate-mapped (YFP+) cell in the inner ml is shown. $\boldsymbol{E}$-J, Mosaic images of YFP immunohistochemistry in Ascl1 ${ }^{\text {CreER }}$ GIFM animals when Tm was administered at E13.5 (E), E14.5 (F), E17.5 (G), P0 (H), P1 (I), and P4 (J). $\boldsymbol{K}$, A comparison of the percentage of each cell type marked at different time points during development is shown (mean $\pm \mathrm{SEM} ; n=3$; unpaired $t$ test). The white dotted line indicates pial surface, the red dotted line indicates border between Pcl and igl, and the yellow dotted line indicates border between igl and wm. Pcl, Purkinje cell layer. Scale bar: A-D, $20 \mu \mathrm{m} ; \boldsymbol{E}-\boldsymbol{J}, 100 \mu \mathrm{m}$.

arrowheads). Using Ascl ${ }^{\text {CreER }}$ GIFM, we found that, when Tm was administered at E13.5 or E14.5, only a few marked cells incorporated BrdU $24 \mathrm{~h}$ after Tm administration (Fig. $1 R-R^{\prime \prime}$, pink arrowheads) (data not shown). When Tm was administered at E17.5 or P1, we also found that very few marked cells incorporated BrdU $24 \mathrm{~h}$ later or were positive for Ki67 (Fig. 1T-T") (data not shown). When the proliferative state of fate-mapped cells was analyzed using Ki67 (which labels most of the cell cycle) $3 \mathrm{~d}$ after Tm was administered at E17.5, we also observed very few $\beta$ gal + cells that were Ki67+ (Fig. 1S'). Furthermore, we found that the majority of $\beta$ gal + cells expressed Pax2, a postmitotic interneuron progenitor marker (Fig. $1 S^{\prime \prime}$ ), although some expressed the oligodendrocyte progenitor marker Olig2 (data not shown) or the astrocyte progenitor marker Sox9 (data not shown).

In summary, our data show that each class of cerebellar interneuron precursor expresses Ascl1 in a distinct temporal pattern that correlates with the final inside-to-outside position the cells will attain. Additionally, our studies suggest that Golgi cells preferentially come from vz progenitors that express Ascl1, whereas stellate and basket cells are primarily, but not solely, 


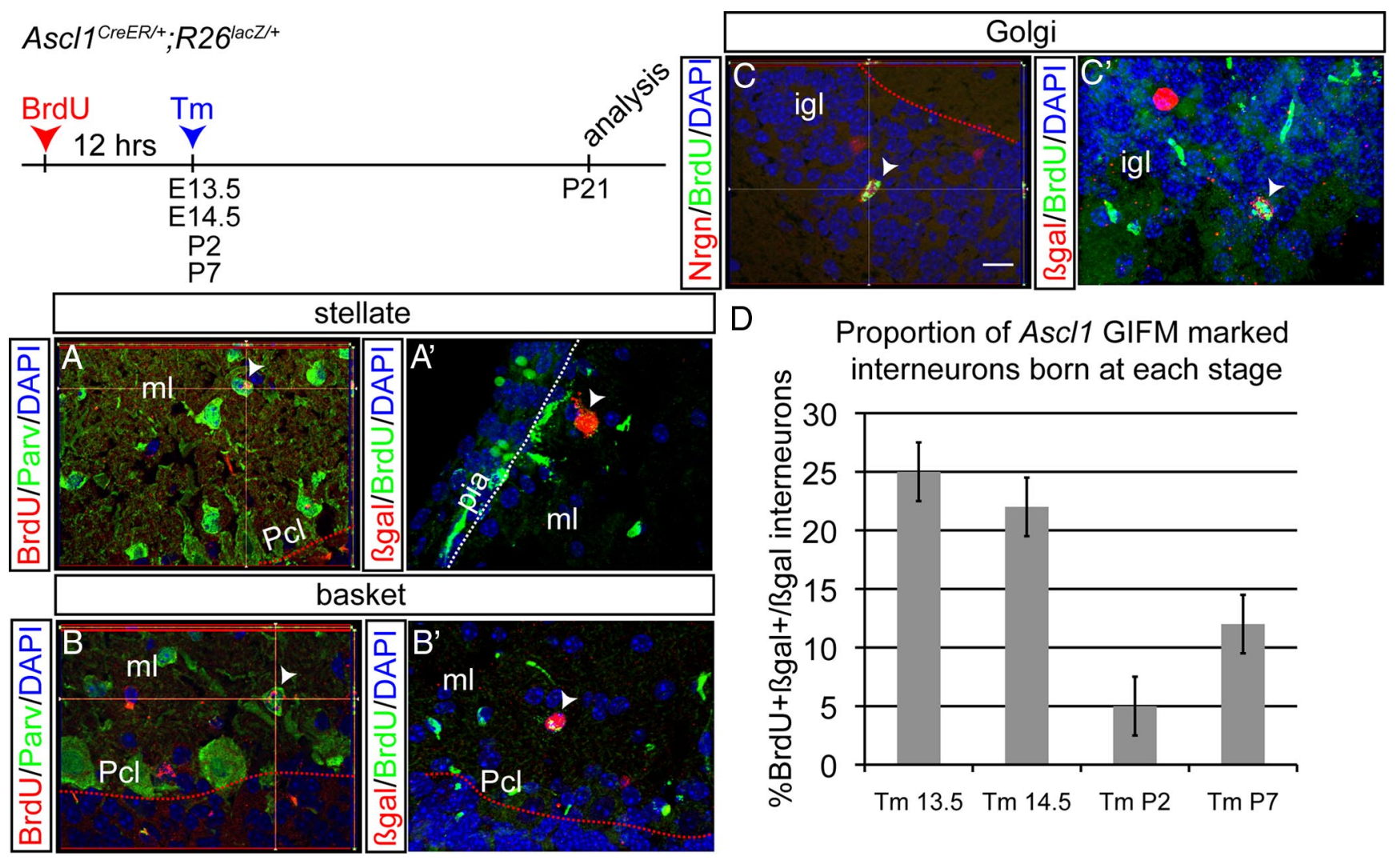

Figure 5. A population of cerebellar interneurons is born during embryonic development. BrdU was administered $12 \mathrm{~h}$ before Tm administration at E13.5, E14.5, $P 2$, and P7. A, Double-labeling immunohistochemistry in the outer $\mathrm{ml}$ for BrdU (red) and parvalbumin (green) shows some stellate cells are born at E14.5. $\boldsymbol{A}^{\prime}$, Double-labeling immunohistochemistry for $\beta \mathrm{gal}$ (red) and BrdU (green) shows an Ascl7 ${ }^{\text {CreeR }}$ GIFM fate-mapped stellate cell born embryonically. B, Double-labeling immunohistochemistry in the inner ml for BrdU (red) and parvalbumin (green) shows some basket cells are born at E14.5. B', Double-labeling immunohistochemistry for $\beta$ gal (red) and BrdU (green) shows an Ascl1 ${ }^{\text {CreeR }}$ GIFM fate-mapped basket cell born embryonically. C, Double-labeling immunohistochemistry in the igl for BrdU (green) and neurogranin (red) shows some Golgi cells are born at E14.5. $C^{\prime}$, Double-labeling immunohistochemistry for $\beta$ gal (red) and BrdU (green) shows

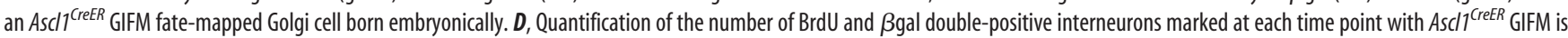
shown (mean $\pm \mathrm{SEM} ; n=3$; unpaired $t$ test). Pcl, Purkinje cell layer; pia, pial surface. Scale bar, $20 \mu \mathrm{m}$.

derived from Ascl1-expressing progenitors in the wm. Ascll ${ }^{\text {CreER }}$ GIFM can also be used for genetically birth dating cerebellar interneurons at embryonic stages, and possibly postnatal stages.

\section{Bergmann glia, astrocyte, and oligodendrocyte precursors} express Ascl1 in unique temporal patterns

Glial cells play a critical role in development and functioning of the cerebellar microcircuitry. The $\mathrm{Bg}$ are a specialized type of astrocytes that provide a framework for Pc dendrite outgrowth and synapse formation (Yamada et al., 2000; Lordkipanidze and Dunaevsky, 2005), as well as the physical structure upon which gcs migrate to the igl (Rakic, 1971). Additionally, ablation of oligodendrocytes in the mouse cerebellum during the first postnatal week results in disorganization of the cortical cytoarchitecture, with abnormal Pc dendritic arborization and axonal fasciculation, as well as impaired migration of interneurons (Mathis et al., 2003). There is also growing evidence that astrocytes function in regulation of synaptic transmission in the CNS (Ullian et al., 2001; Doetsch, 2003; Newman, 2003; Lin and Bergles, 2004).

Fate-mapping studies using either postnatal infection with replication-defective retroviruses to mark cerebellar astrocyte and oligodendrocyte precursors, or Pft1a ${ }^{C r e}$ mice to mark all vzderived cells, have shown that these glial cells arise from the vz and then migrate through the wm and continue to proliferate during early postnatal stages (Zhang and Goldman, 1996a,b; Milosevic and Goldman, 2002; Hoshino et al., 2005). A recent study, however, concluded that cerebellar oligodendrocytes arise from outside the cerebellum (Grimaldi et al., 2009). Finally, previous data using an Ascl1-CreER BAC transgene raised the question of whether Ascl1-expressing cerebellar progenitors give rise only to oligodendrocytes and not to astrocytes or Bg (Kim et al., 2008).

Since we observed Ascl 1 expression in both the $\mathrm{vz}$ and wm at E17.5, cells derived from either region could account for our observed marking of glia with Ascl1 ${ }^{\text {CreER }}$ GIFM after E16.5. At earlier stages, Ascll ${ }^{\text {CreER }}$ must mark precursors as they leave the vz region. Since the three different types of cerebellar glia have distinct morphologies, we used the $R 26 R^{Y F P}$ reporter line as one means to identify the three types of glia based on their morphology. Interestingly, we found that $\mathrm{Bg}$ were marked with $A$ scll ${ }^{\mathrm{CreER}}$ GIFM only when Tm was administered at E13.5, whereas oligodendrocytes and astrocytes were labeled at all stages after E12.5. The identity of Bg was confirmed by their distinct morphology (small cell bodies and long radial fibers with glial endfeet at the pial surface), location within the Pc layer, and expression of GFAP (Fig. $\left.6 A, A^{\prime}\right)$. Oligodendrocytes were identified by their location within the wm, their unique morphology (flat cell bodies with parallel oriented radial processes), and coexpression of CAII (Fig. 6B, $B^{\prime}$ ), whereas astrocytes were identified by their small bodies and many processes, as well as expression of GFAP (Fig. $6 C, C^{\prime}$ ).

Next, we determined whether there is a temporal bias as to when cerebellum oligodendrocytes and astrocytes are marked 


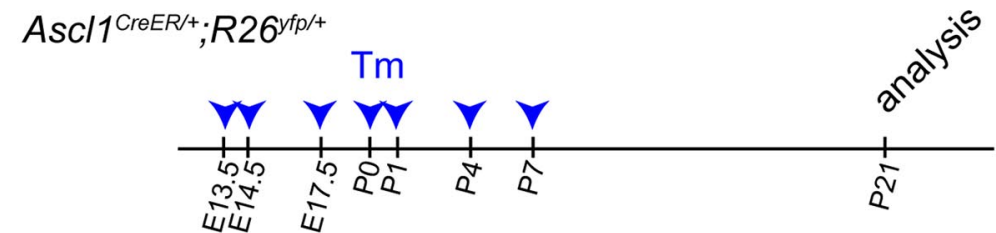

\begin{tabular}{|c|c|c|}
\hline Bergmann glia & oligodendrocyte & astrocyte \\
\hline
\end{tabular}
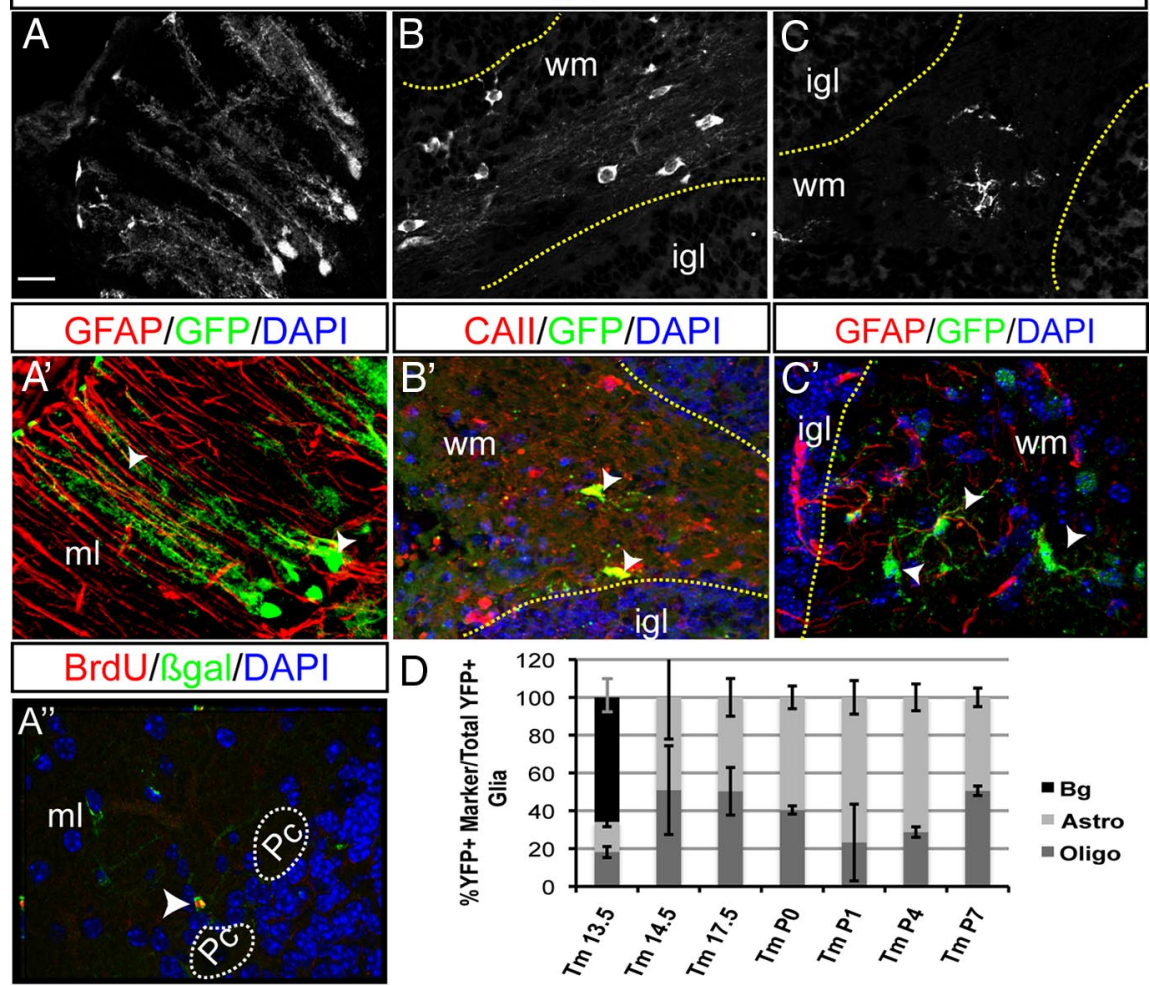

Figure 6. Temporal fate mapping of cerebellar glia with Asc/1 ${ }^{\text {CreER }} \mathrm{GIFM}$ reveals marking of Bergmann glia only at one time point and other glia during their proliferative phase. Ascl1 ${ }^{C r e E R} \mathrm{GIFM}$ marking of Bergmann glia $\left(\boldsymbol{A}-\boldsymbol{A}^{\prime \prime}\right)$, oligodendrocytes $\left(\boldsymbol{B}, \boldsymbol{B}^{\prime}\right)$, and astrocytes $\left(\boldsymbol{C}, \boldsymbol{C}^{\prime}\right)$ is shown. $\boldsymbol{A}^{\prime}$, Double-labeling immunohistochemistry for GFAP (red) and YFP (green) confirms the identity of Bergmann glia. $\boldsymbol{A}^{\prime \prime}$, BrdU was administered $12 \mathrm{~h}$ before Tm administration at E13.5. Double-labeling immunohistochemistry for BrdU (green) and $\beta \mathrm{gal}$ (red) shows Ascl1 ${ }^{\text {CreER }}$ GIFM and long-term BrdU-marked Bergmann glia. $\boldsymbol{B}^{\prime}$, The identity of oligodendrocytes is shown by double-labeling immunohistochemistry for CAll (red) and YFP (green). $\boldsymbol{C}^{\prime}$, Double-labeling immunohistochemistry for GFAP (red) and YFP (green) shows some Ascl1 ${ }^{\text {CreER }}$ GIFM-marked cells are astrocytes. $\boldsymbol{D}$, The percentage of each type of

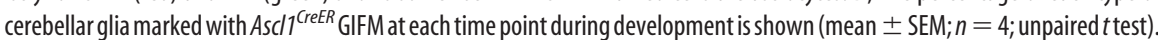
Scale bar, $20 \mu \mathrm{m}$.

with Ascl ${ }^{\text {CreER }}$ GIFM (Fig. 6D). We found that, when Tm was administered at E13.5, astrocytes and oligodendrocytes comprised only $\sim 15$ and $\sim 18 \%$, respectively, of the total YFP + glial population and the rest of the marked glia were Bg. In Ascl $1^{\text {CreER }}$ GIFM mice, when Tm was administered at E14.5 or E17.5, astrocytes and oligodendrocytes were equally represented in the YFP+ glial population (Fig. $6 D$ ). At P0, $\sim 40 \%$ of all marked glia were oligodendrocytes and the rest were astrocytes. Tm administration at P1 and P4 resulted in a greater proportion of cerebellar astrocytes being marked ( $\sim 71-76 \%$ of all YFP + glia) than oligodendrocytes $(\sim 23-28 \%)$. Finally, at P7, astrocytes and oligodendrocytes were marked in similar numbers. These data indicate that the Ascl1-expressing cells in the vz and wm produce all cerebellar glial cell types in a unique temporal pattern during cerebellar development.

Since Bergmann glia were marked only when Tm was administered at E13.5, we tested whether Bergmann glia are marked with $A s c l 1{ }^{C r e E R}$ GIFM around the time of their last cell division.
Strikingly, when BrdU was administered $12 \mathrm{~h}$ before administration of $\mathrm{Tm}$ to Ascl1 ${ }^{\text {CreER }}$ GIFM mice at E13.5, a large percentage of YFP + Bg in P21 mice was found to be double positive for BrdU and Bgal ( 30\%) (Fig. 6A"). In contrast to Bg, $\mathrm{Pcs}$, and interneurons, no YFP+ oligodendrocytes or astrocytes were found to retain $\mathrm{BrdU}$ at $\mathrm{P} 21$.

\section{Conditional ablation of Ascl 1 in the cerebellum results in a reduction in cerebellar interneurons and oligodendrocytes and increase in astrocytes}

Given our finding that Ascll is transiently expressed in all vz-derived cell types, including interneuron and glial precursors in the wm after birth, it is possible that the phenotype reported for Ascll-null mutants at birth does not reflect the entire requirement for Ascl1 during cerebellum development. Since Ascl1-null mutants die at birth (Guillemot et al., 1993), we used a recently generated $A s c l{ }^{\text {loxP }}$ conditional allele (Pacary et al., 2011) to remove Ascl1 specifically in the cerebellum. We reasoned that such mice should be viable and therefore allow us to identify all mature cerebellar cell types. Indeed, using the vz-specific Ptfla ${ }^{\text {Cre }}$ line (Kawaguchi et al., 2002) to selectively delete Ascl1 in vzderived cells of the cerebellum (and a subset of cells in the hindbrain and spinal cord), we found that $\mathrm{Ptfla}^{\mathrm{Cre} /+}$; Ascll ${ }^{\text {loxPlloxP }}$ conditional knock-outs (Ptfla-Ascl1 ckos) were viable. The conditional mutants also did not have any obvious locomotor defects. The deleted $A s c l 1^{l o x P}$ allele $\left(A s c l{ }^{\Delta}\right)$ functions as a null allele, since similar to Ascl1-null mutants (Grimaldi et al., 2009), we found that Ascl1 ${ }^{\text {CreER/A }}$ E18.5 embryos had a decrease in postmitotic Pax2+ cells (cerebellar interneuron progenitors), and proliferating Olig2+ oligodendrocytes (data not shown).

We first determined whether the overall size and foliation pattern was altered in mice lacking Ascl1. Hematoxylin and eosinstained sagittal sections of P21 Ptfla-Ascll ckos revealed a normal foliation pattern and basic cortical laminar organization (Fig. $7 A, B)$. However, the overall size of the cerebellum appeared slightly reduced in Ptfla-Ascl1 ckos compared with littermate controls, and there was a clear reduction in the number of interneurons in the $\mathrm{ml}$ (Fig. 7C,D). Quantification of the circumference of the cerebellum in a series of sections across the M-L axis revealed that the cerebellum of Ptfla-Ascll cko mutants was indeed reduced by $\sim 15 \%$ (average length of $36.5 \mathrm{~mm}$ in controls compared with $31.3 \mathrm{~mm}$ in mutants; $p<0.01$ ) (Fig. 7J). Quantification of Pc density and the overall thickness and density of cells in the igl revealed no difference between Ptfla-Ascl1 ckos and controls (Fig. $7 A, B, I$ ). Since the length of the Pc layer is reduced but the density of Pcs is normal, the total number of Pcs must be slightly reduced in Ptfla-Ascll ckos. The overall mor- 


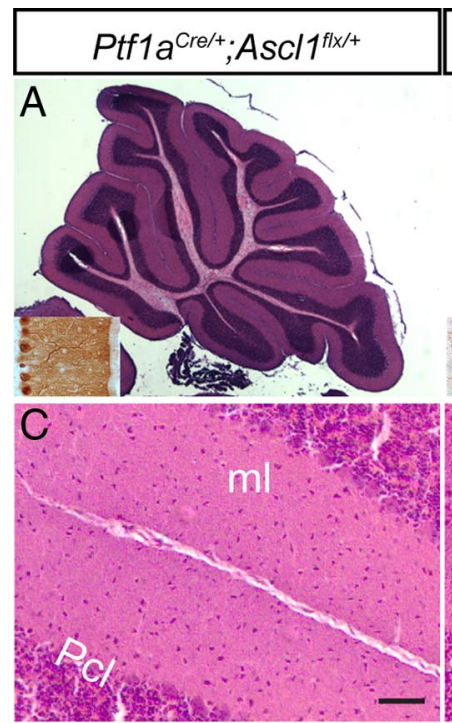

\section{Purkinje cell density [\#Pcs/mm]}

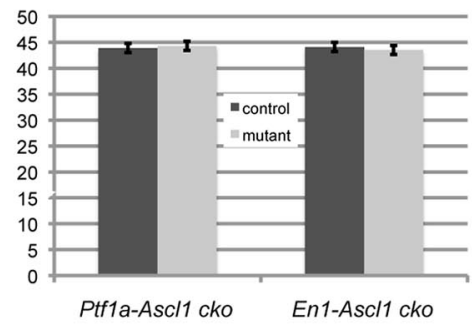

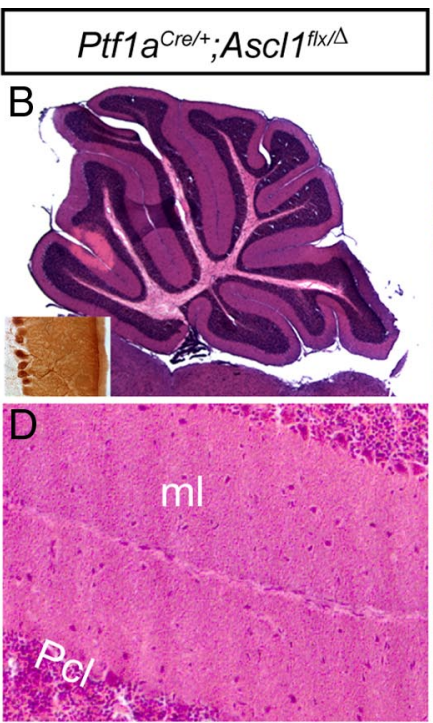

$\mathrm{J}$

$\mathrm{Cb}$ circumference

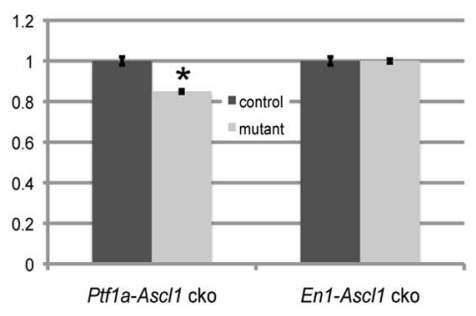

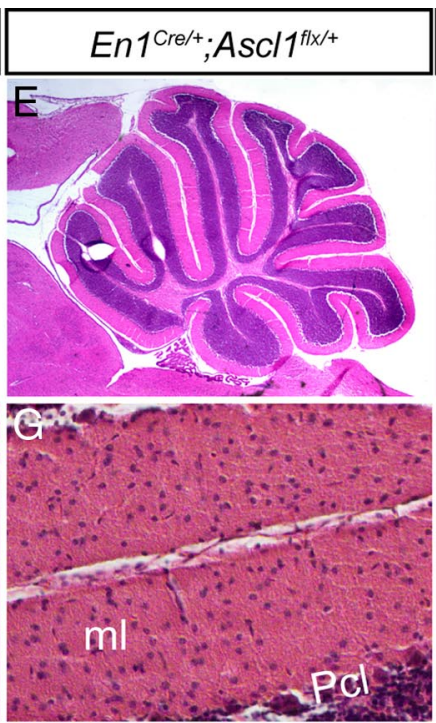

$E n 1^{\mathrm{Cre} / \mathrm{t}} ; A s c / 1^{f \times / \Delta}$

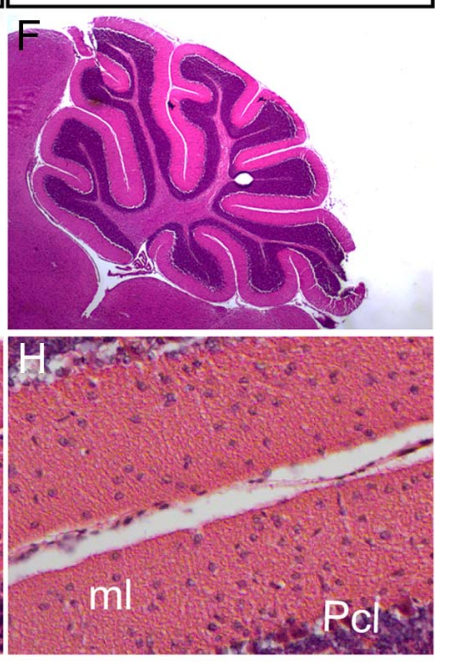

$\mathrm{K}$
Number of vz-derived cell types

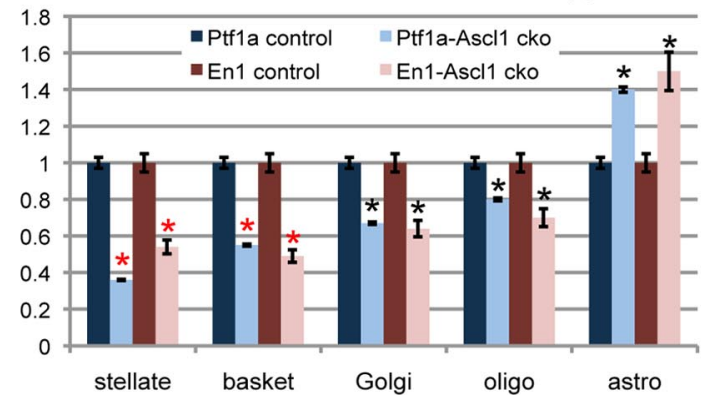

Figure 7. Conditional deletion of Ascl1 in the cerebellum differentially affects the number of interneurons and glia in the adult. Hematoxylin and eosin (H\&E)-stained sections show smaller cerebellum in a Ptf1a-Ascl1 cko $(\boldsymbol{B})$ compared with a littermate control $(\boldsymbol{A})$. The insets in $\boldsymbol{A}$ and $\boldsymbol{B}$ are immunostaining for calbindin showing no difference in the overall morphology of Pcs. $\mathrm{H} \& \mathrm{E}$-stained sections of En1-Ascl1 ckos $(\boldsymbol{F})$ show a similar cellular phenotype to Ptf1a-Ascl1 ckos $(\boldsymbol{A})$. Higher magnification images show severe reductions in the number of ml interneurons in both ckos $(\boldsymbol{D}, \boldsymbol{H})$ compared with littermate controls $(\boldsymbol{C}, \boldsymbol{G})$. I, Quantification of the number of Purkinje cells per millimeter in Ptf1a-Ascl1 and En 1-Ascl1 ckos and littermate controls. J, Quantification of the average cerebellar circumference in Ptf1a-Ascl1 and En1-Ascl1 ckos and littermate controls with controls set as 1 shows significantly smaller cerebellum size in Ptf1a-Ascl1 ckos ( $p=0.01$ ) but not En1-Ascl1 ckos. K, Quantification of the GABAergic interneurons and glia in Ptf1a-Ascl1 and En1-Ascl1 ckos and littermate controls with average control numbers set as 1 (mean \pm SEM; Ptf1a-Ascl1 cko, $n=3 ;$ Ptf1a-Ascl1 control, $n=3 ; E n 1$-Ascl1 cko, $n=3 ;$ En1-Ascl1 control, $n=3$; unpaired $t$ test; the red asterisk depicts $p<0.003 ;$ the black asterisk, $p<0.05)$. Scale bar: $\boldsymbol{A}, \boldsymbol{B}, \boldsymbol{E}, \boldsymbol{F}, 100 \mu$ m; C, D, G, H, $20 \mu \mathrm{m}$.

phology of Pcs appeared normal based on IHC labeling of Pcs with a calbindin antibody in Ptfla-Ascl1 ckos (Fig. $7 A, B$, inset).

We next tested whether the three types of cortical interneurons derived from Pax2-expressing immature interneurons around birth are equally affected by loss of Ascl1 throughout cerebellum development. Interestingly, we found that, in PtflaAscll ckos, the interneurons located in the outer $\mathrm{ml}$ (stellate cells) were reduced to the greatest extent (by $\sim 64 \%$ ), and the next most affected interneurons were the basket cells (reduced by $\sim 45 \%$ ), with GABAergic Golgi interneurons in the igl being reduced the least ( $33 \%)$ (Fig. $7 K)$. Thus, although Pax + cells are greatly diminished in Ascl1-null mutants at birth, before the time when the majority of stellate interneurons are generated, it is the stellate interneurons that are ultimately depleted the most in Ptfla-Ascl1 ckos.

We next determined whether the balance of cerebellar oligodendrocytes and astrocytes was altered in Ptfla-Ascll ckos, as null mutants were reported to have a significant decrease in Olig2+ oligodendrocyte progenitors and slight increase in Sox9+ astrocyte precursors at birth. Quantification of the number of oligodendrocytes in Ptfla-Ascl1 ckos at P21 revealed a $\sim 25 \%$ reduction in PtflaAscl1 ckos compared with controls (Fig. $7 \mathrm{~K}$ ), and a $\sim 30 \%$ increase in the number of astrocytes in Ptfla-Ascll cko mutants (Fig. $7 K$ ). In summary, Ascll expression in progenitors is necessary for the generation of the proper relative proportions of GABAergic interneurons and the two major types of glia. Furthermore, the interneurons that express Ascl1 latest in development are preferentially dependent on Ascl1, and Pcs appear to have only a minor requirement for Ascll.

We reasoned that one possibility for the mild phenotype in early-born cerebellum neurons in Ptfla-Ascl1 ckos could be that the Ptfla ${ }^{C r e /+}$ allele deletes Ascl1 after it begins to be expressed, and thus the phenotype of Ptfla-Ascll ckos could represent a hypomorphic phenotype. Indeed, analysis of lacZ expression in E15.5 Ptf $1 a^{\mathrm{Cre} /+}$;Rosa ${ }^{\text {loxP-STOP-lacZ/+ }}$ embryos revealed that postmitotic cells were primarily marked, with only a few scattered marked cells in the vz (data not shown) (Pascual et al., 2007). We therefore generated another Ascl1 cko mutant using $E n 1^{\text {Cre }}$, which deletes floxed genes in all cells of the cerebellum by E9 (Kimmel et al., 2000; Li et al., 2005). IHC analysis of the cerebellum primordium from E11 En1-Ascl1 ckos confirmed that Ascl1 protein was mostly absent at this stage (data not shown). Analysis of sagittal sections of P21 En1-Ascl1 ckos stained with hematoxylin and eosin, or using IHC with cell type-specific markers, how- 
ever, revealed a similar cellular phenotype to Ptf1a-Ascl1 ckos (Fig. $7 E-K$ ) (data not shown). GABAergic basket and stellate interneurons were reduced by 51 and $46 \%$, respectively, and Golgi interneurons were reduced by 30\% (Fig. 7K). Quantification of glia in En1-Ascll ckos revealed that oligodendrocytes were reduced significantly (by 30\%) and astrocytes increased by $34 \%$ compared with littermate controls (Fig. $7 \mathrm{~K}$ ). The quantification of the different cell types in the two Ascll ckos was similar except that interestingly stellate interneurons appeared to be more reduced in Ptfla-Ascl1 ckos than in En1-Ascl1 ckos. Moreover, we found no difference in the circumference of the cerebellum of En1-Ascl1 ckos compared with littermate controls (27.4 and 26.5 $\mathrm{mm}$, respectively). Our finding that Ascll ckos lacking one copy of the related bHLH gene Ptfla have a stronger phenotype than mice lacking only Ascll in the cerebellum suggests there is overlap in the functions of the two genes in regulating generation of Pcs and stellate interneurons.

To address whether other bHLH genes could also contribute to the milder cerebellar phenotype in Ascl1 ckos compared with Ptfla-null mutants that lack all GABAergic cell types (Hoshino et al., 2005; Pascual et al., 2007), we analyzed Neurogenin1 (Ngn1) and Ngn2 expression in Ascl1-null mutants at E12.5. As previously reported (Zordan et al., 2008), Ngn2 but not Ngn1 was expressed in the same region of the cerebellum as Ascl1 after E11.5. Furthermore, no obvious difference in expression of either gene was detected in Ascl1-null mutants (data not shown), suggesting only $\mathrm{Ngn} 2$ could compensate for Ascl1 loss. Additionally, we examined Delta1 and Delta3 expression at E12.5 and found that expression of both genes was only slightly decreased in some Ascl1-null mutants throughout M-L axis (data not shown). It is possible that Ngn2 prevents a major downregulation of Delta1/3 expression in the cerebellar vz of Ascl1-null mutants. Together, our two Ascll ckos demonstrate that Ascl1 is preferentially required in the cerebellum for production of late-born GABAergic interneurons and to produce the correct balance of oligodendrocytes and astrocytes.

\section{In the absence of Ascl1, some cerebellum vz progenitors} acquire a gcp phenotype

Curiously, fate mapping in $\mathrm{Ptfl} \mathrm{a}^{\mathrm{Cre} / \mathrm{Cre}} ; \mathrm{Rosa}^{\text {lacZ/+ }}$ mice revealed that a greater proportion of fate-mapped cells reside in the egl of homozygous Ptfla-null mutants than in Ptfla ${ }^{C r e /+} ; R_{0 s a} a^{\text {lacZ/+ }}$ heterozygous controls (Pascual et al., 2007), suggesting a switch in fate of vz progenitors to url progenitors. One potential problem with interpreting the results of the $\mathrm{Ptfla} \mathrm{a}^{\mathrm{Cre} / \mathrm{Cre}}$ fate-mapping study is that, in the homozygous mutants, the level of Cre protein should be double that in Ptfla $a^{\mathrm{Cre} /+}$ heterozygotes, and thus the marking of more cells in the egl of Ptfla $a^{\text {Cre/Cre }}$ mice could be due to more cells initially being marked (i.e., cells with a low level of Cre in heterozygotes might not be marked, whereas the same cells in homozygotes will express a sufficient level of Cre to induce recombination of the reporter allele). To determine whether the fate of Ascl1-expressing cells is altered in the absence of Ascl1 function, we performed a fate-mapping study in $A s c l 1^{\mathrm{CreER} / \Delta}$; Rosa ${ }^{\text {lacz/+ }}$ animals.

Strikingly, we found that when Tm was administered at E10.5, E11.5, or E12.5 to Ascl1 ${ }^{\mathrm{CrEER} / \Delta} ;$ Rosa $^{\text {lacZ/+ }}$ animals and the cerebellum analyzed at E17.5, not only were Pcs marked and cn interneurons (only at E10.5 marking), but also cells located within the egl were marked (Fig. $8 A, B^{\prime \prime}$ ). Consistent with GIFM using an Atoh1-CreER transgene to mark gcps at these time points of Tm administration (Machold and Fishell, 2005), we found that most of the marked gcps were located in the anterior half of the cere- bellum at E17.5 (location of the earliest generated gcps) (Fig. 8 B). Double IHC staining for $\beta$ gal and Pax6, a marker for gcps, confirmed that the Ascl1 ${ }^{\text {CreER }}$ fate-mapped cells located in the egl were gcps (Fig. $8 B^{\prime \prime}$ ). Interestingly, we did not find any Tbr2 $+\mathrm{cn}$ projection neurons marked in $\mathrm{Ascl1}^{\mathrm{CrEER} / \Delta}$; Rosa ${ }^{\text {lacZ/+ }}$ mutants (data not shown). Furthermore, when Tm was administered at E13.5 or E14.5 to Ascl1 ${ }^{\mathrm{CrEER} / \Delta} ; \mathrm{Rosa}^{\text {lacZ/+ }}$ animals and the cerebellum analyzed at E17.5, no marked cells were detected in the egl, but as expected the population of Pax $2+$ marked cells was reduced (Fig. $\left.8 C, D^{\prime \prime}\right)$. Additionally, we used the $P t f 1 a^{C r e}$ allele to fate map vzderived cells in $\mathrm{Ascl1}^{\mathrm{CreER} / \mathrm{CreER}}$-null animals in the absence of Tm administration. Compared with $\mathrm{Ptfla}^{\mathrm{Cre} /+} ; \mathrm{Rosa}^{\text {lacZ/+ }}$ animals, nearly twice as many gcps were marked in $\mathrm{Ptfla} \mathrm{Cre} /+^{\mathrm{C}} ; \mathrm{Ascll}{ }^{\mathrm{CreER} / \mathrm{CreER} \text {; }}$ Rosa ${ }^{\text {lacZ/+ }}$ mutants (Fig. 8E,F) (for Ptfla $\mathrm{Cre}^{\mathrm{C}} ;$ Rosa ${ }^{\text {lacZ/+ }}$ fate mapping, see also Pascual et al., 2007). Quantification of the number of $P t f 1 a^{C r e}$ fate-mapped gcps showed that $\sim 12$ gcps were marked per $100 \mu \mathrm{m}$ of egl in Ascl1 $^{+/+}$E18.5 embryo cerebellum sections compared with $\sim 20$ gcps per $100 \mu \mathrm{m}$ of egl in Ascl1-null embryos. Finally, Atoh1 expression was used to mark the url and gcps at E12.5 in Ascl1 ${ }^{\mathrm{CreER} / \Delta}$; Rosa ${ }^{\text {lacZ/+ }}$ animals, but no major difference in expression was detected compared with controls (data not shown). It is possible that, since only a small number of gcps is labeled in Ascl1 ${ }^{\text {CreER/A}} ;$ Rosa $^{\text {lacZ/+ }}$ embryos, any change in Atohl expression would be subtle and difficult to detect. Together, the results of our fate-mapping studies suggest that Ascl1 is required before E13 to ensure vz cells do not enter the url.

\section{Discussion}

Ascl1 ${ }^{\text {CreER }}$ GIFM is a powerful tool for characterizing all cell types derived from the cerebellar vz

Our $A s c l 1^{C r e E R}$ GIFM study demonstrates that Ascl1 is transiently expressed by precursors of all cell types thought to be derived from the cerebellar vz. One significant difference between the recently described Ascl1-CreER BAC transgenic line (Kim et al., 2008) and the CreER knock-in allele is that $A s c l 1^{\text {CreER }}$ marks all the GABAergic interneurons (Golgi, stellate, basket, and candelabrum), as well as Bg and astrocytes, in addition to Pcs and oligodendrocytes. A second significant difference is that, except for $\mathrm{Bg}$, the $\mathrm{Ascl1}{ }^{\mathrm{CreER}}$ allele marks progenitors throughout the period of their generation in the vz and wm. Furthermore, Pcs and embryonic interneurons are marked around the time of their last of cell division. Interestingly, $A s c l 1^{\text {CreER }}$ also birth dates $\mathrm{Bg}$, but only those in the vz leaving the cell cycle at $\sim$ E14 and not those that later divide in the Pc layer (Shiga et al., 1983). The power of our Ascl1 ${ }^{C r e E R}$ GIFM approach is highlighted by comparison to previous fate mapping of the cerebellar vz with $\mathrm{Ptfl} \mathrm{a}^{\mathrm{Cre}}$ (Hoshino et al., 2005; Pascual et al., 2007) where the cumulative nature of cell marking obscured the location and relationship between temporal marking and final position of cells.

\section{Purkinje cells with similar birth dates populate distinct A-P and $\mathrm{M}-\mathrm{L}$ positions}

The inherent Ascll expression in newly differentiating cells enabled us to generate the first genetic temporal birth-dating fate map of Pcs. We found that cohorts of Pcs born around the same time occupy distinct positions along the A-P and M-L axes of the adult cerebellum. The finding that Pcs successively settle in M-L parasagittal stripes and A-P zones raises the possibility that distinct functional properties of Pcs could be specified in progenitors as they leave the $\mathrm{vz}$ and express Ascll. There is ample evidence for distinct functional domains within the cerebellum. The spinocerebellar tract projects only to vermis lobules $\mathrm{I}-\mathrm{V}$ and VIII/IX. Afferents resolve into parasagittal bands after birth, 


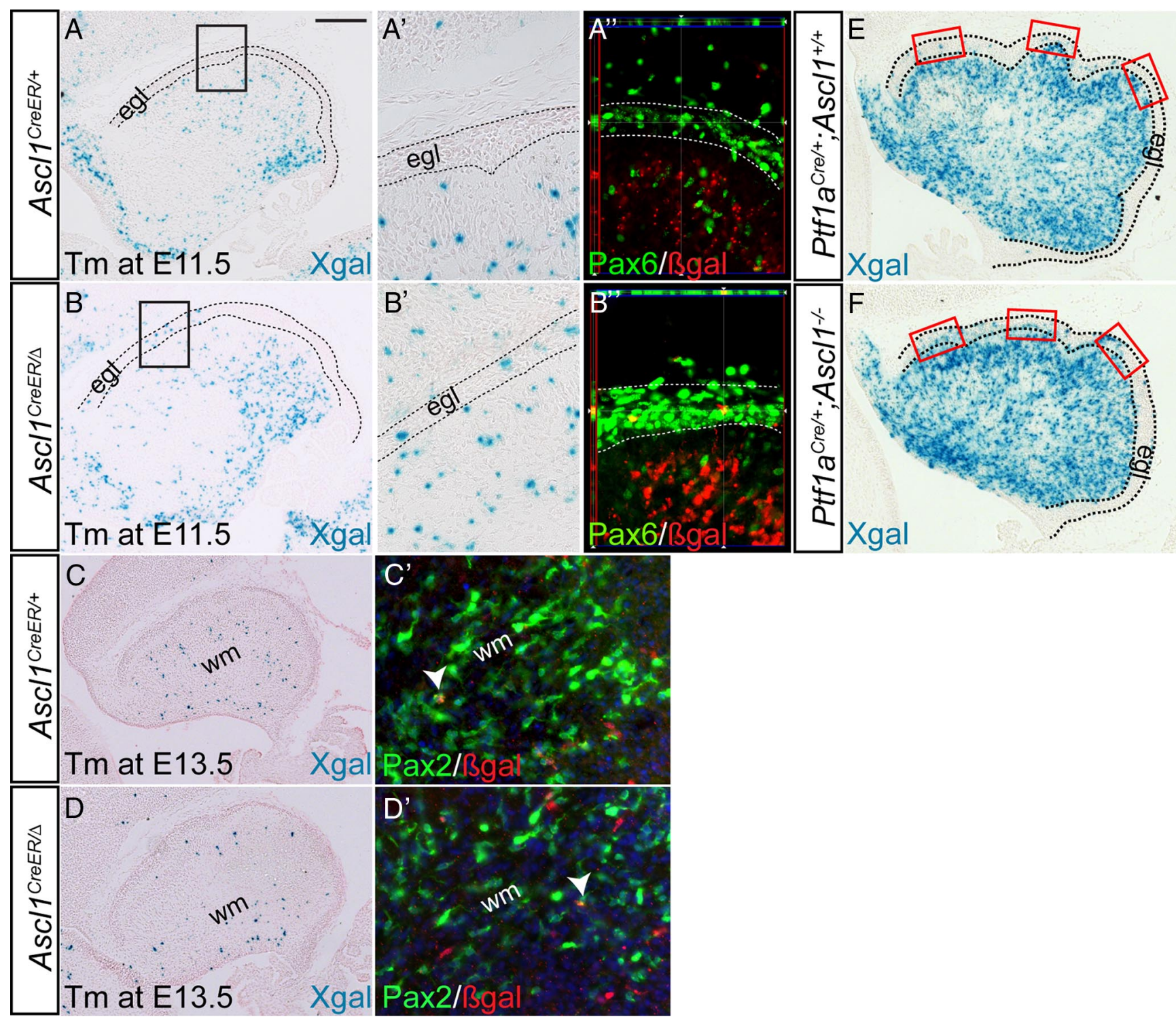

Figure 8. In the absence of Ascl1, granule cell precursors are marked with $A s C 17^{\text {CreeR }}$ GIFM. $A, A^{\prime}$, Xgal staining of cerebellar sections of E17.5 Ascl $7^{\text {CreeR/ } /+} ; R 26^{\text {lacZ/+ }}$ mice administered Tm at E11.5 showing marking of only Pcs, in contrast to $A s c 17^{\text {reeER/ }} ; R 26^{l a c Z /+}$ mice in which gcps in the egl (dotted outline) are marked in addition to Pcs $\left(B, B^{\prime}\right) . A^{\prime \prime}, B^{\prime \prime}$, Double-labeling immunohistochemistry

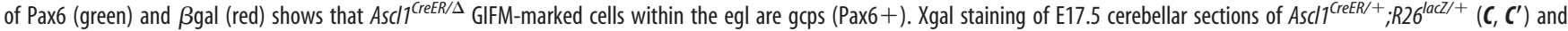

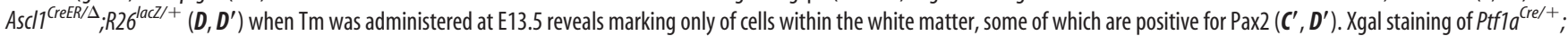

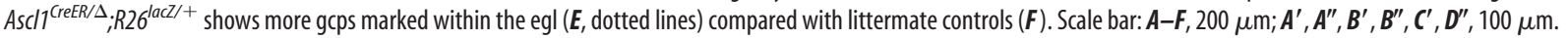

which are mirrored by parasagittal Pc gene expression patterns (Larouche and Hawkes, 2006; Sillitoe and Joyner, 2007; Sillitoe et al., 2010). Information encoded in Pcs based on their birth date and transient expression of Ascll could therefore contribute to the complexity of Pc molecular identity and circuitry in the adult.

\section{GABAergic cerebellar interneurons are sequentially generated from inside to outside}

Our GIFM results provide the most detailed description of the temporal pattern of interneuron generation in the mouse cerebellum. Previous studies have suggested that cerebellar interneurons are generated mainly during early postnatal stages in rodents (Zhang and Goldman, 1996a). $\left[{ }^{3} \mathrm{H}\right]$ Thymidine birth-dating studies in the rat indicated sequential generation of cortical interneurons, Golgi (E14-P3), basket (P3-P9), and stellate (P5P12) (Altman and Bayer, 1997), similar to the sequence seen in monkey (Rakic, 1973). BrdU birth-dating and retroviral labeling studies in mouse and rat suggested that the vast majority of interneurons come from proliferating progenitors in the wm thought to be derived from the vz (Zhang and Goldman, 1996a,b; Milosevic and Goldman, 2002, 2004; Leto et al., 2009). Additionally, it was proposed that the positional (inside-to-outside) and neurochemical identities of GABAergic interneurons are specified within the wm (Leto et al., 2009). In our study, we demonstrate that the deepest located interneurons of the $\mathrm{cn}$ are generated first from the vz $(\sim \mathrm{E} 11)$, followed primarily by the Golgi subpopulation of interneurons ( $\sim$ E14-E18). At early postnatal stages (until $\sim$ P7), the remaining $\mathrm{ml}$ interneurons are then generated in the wm (basket and candelabrum before stellate). Our results raise the question of whether the progenitors in the vz and wm constitute separate progenitor populations, or whether a common progenitor initially generates all three interneuron types in the vz and then moves to the wm where it preferentially generates $\mathrm{ml}$ interneurons. It is tempting to speculate that the 


\section{A Summary of marking of GABAergic neurons and glia with Ascl1 ${ }^{\text {CreER }}$}

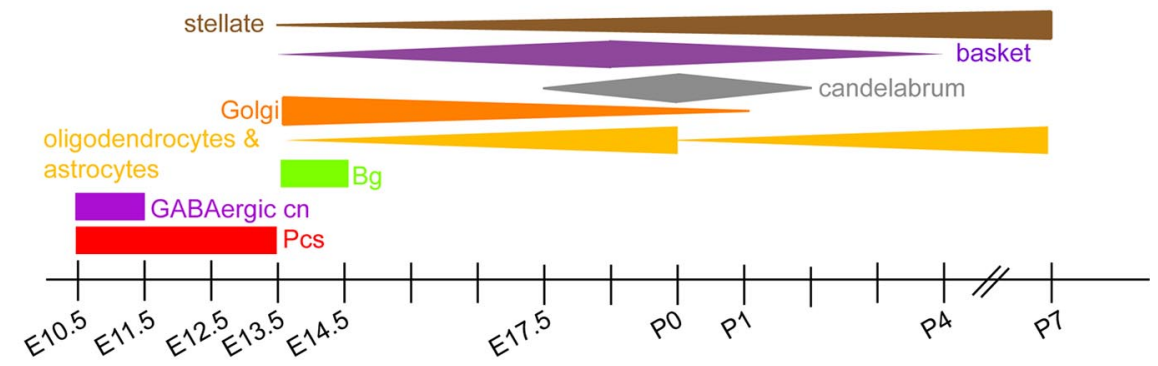

B Model

$$
\text { E10.5-E13.5 E13.5-P0 }
$$
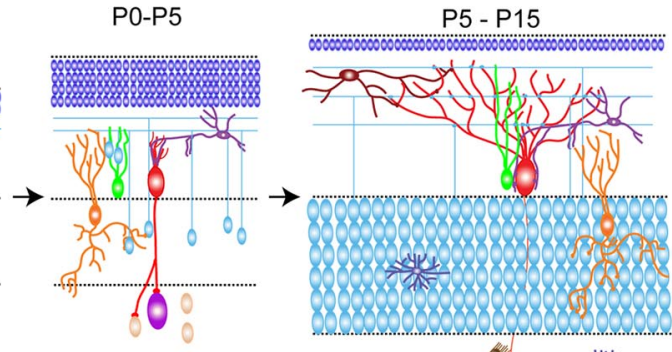

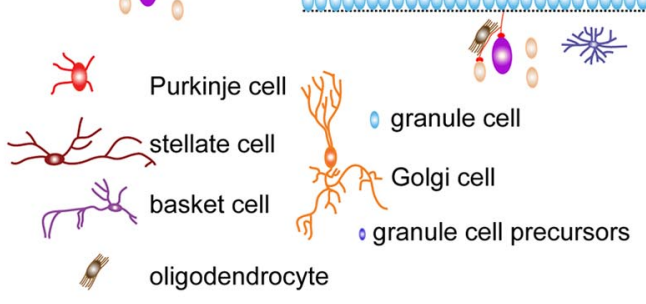

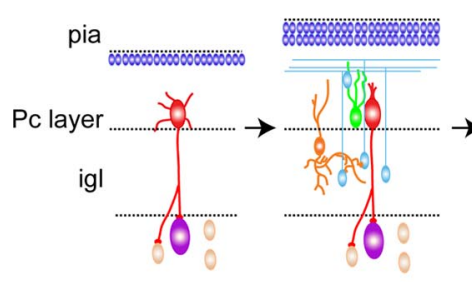

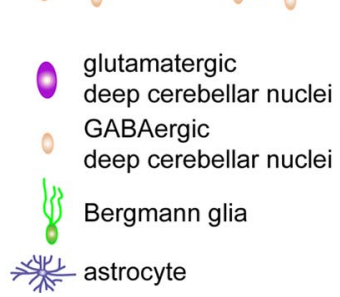

Figure 9. Model for the temporal generation of the cells that form the cerebellar local circuitry. A, Summary of the time points at which vz-derived cells are preferentially marked using $A s C / 7^{\text {CreER }}$ GIFM. The thickness of the line indicates the relative number of each cell type marked at different time points. B, During early embryogenesis (E10.5-E13.5), Pcs and neurons of the $\mathrm{cn}$ are born and begin to make contacts. During mid and late embryogenesis (E13.5-P0), a population of $\mathrm{Bg}$ and Golgi interneurons are born. Bg migrate to their final position within the Pc layer to guide newly differentiated gcs toward the igl. Golgi interneurons and gcs within the igl then form synaptic contacts within glomeruli. During early postnatal stages (P0-P5), basket interneurons are primarily generated and contact $\mathrm{Pc}$ apical dendrites. Finally, during late postnatal stages (P5-P15), stellate interneurons are mainly generated and occupy the outer region of the $\mathrm{ml}$, and start making contacts with Pc dendrites. Astrocytes and oligodendrocytes are generated after birth and contact their target neurons. Thus, target neurons are generated before the neurons or glia that contact them are generated.

small population of early-born ml interneurons lay down a skeleton of the ultimate interneuron circuit, and possibly provide cues for the later-born interneurons of the same type to differentiate in the correct location.

\section{Ascl1 is preferentially required for generation of the late-born GABAergic cerebellar neurons}

By generating two cerebella-specific Ascl1 cko mutants that survive to adulthood, we discovered that, unlike Ptfla, Ascl1 is necessary to generate only a subset of vz-derived cell types. Ascll is required to generate a full complement of GABAergic interneurons, as well as the appropriate ratio of oligodendrocytes and astrocytes $\left(\mathrm{EnI}^{\mathrm{Cre} /+} ; \mathrm{Ascll}^{\text {loxP/loxP }}\right.$ mutants). Interestingly, the $\mathrm{ml}$ interneurons appear to be the most sensitive to loss of Ascll, indicating that the later the birth of a neuron the greater its dependence on Ascll. Furthermore, there appears to be an overlap in function between Ascl1 and Ptfla as there is a greater reduction in stellate interneurons and a slight reduction in Pcs when one allele of Ptfla is removed in Ascl1 ckos (Ptfla ${ }^{C r e /+}$; Ascll ${ }^{\text {loxPlloxP }}$ mutants). Our results are particularly important since an analysis of Ascl1-null mutants showed a large reduction in Pax2+ (postmitotic) cells at birth, which based on birth-dating studies should primarily be Golgi interneuron precursors generated from the vz.
However, we uncovered that it is actually the interneurons born primarily after birth in the wm that appear to be preferentially reduced in the absence of Ascll. Since the number of proliferating cerebellar cells was reduced in Ascl1-null mutants at E18.5 (Grimaldi et al., 2009), one role for Ascl1 might be to promote proliferation. Alternatively, since few proliferating cells express Ascl1 after E10.5, Ascl1 might inhibit differentiation. Therefore, in Ascl 1 mutants, the pool of proliferating progenitors would be reduced prematurely.

Our phenotype analysis revealed a decrease in oligodendrocytes and an increase in astrocytes in adult Ascl 1 ckos, indicating that Ascl1 has opposite effects on these two glia cell types. If a common progenitor gives rise to both glial cell types, then one possibility is that Ascl1 promotes an oligodendrocyte fate and inhibits an astrocyte fate. Consistent with this, previous studies in the cerebral cortex (Parras et al., 2004, 2007) and spinal cord (Sugimori et al., 2007) showed that Ascl1 is required to specify oligodendrocyte precursors and to repress the astrocytic fate. However, a recent study provided evidence that the majority of cerebellar oligodendrocytes are generated from outside the cerebellum (Grimaldi et al., 2009), arguing against a common progenitor. As we found that Ascl1 is expressed in proliferating oligodendrocyte (Olig2+) and astrocyte (Sox9+) progenitors, our mutant study indicates that Ascl1 promotes oligodendrocyte and inhibits astrocyte precursor expansion.

Finally, our fate-mapping studies in Ascl1-null mutants using Ptfla ${ }^{\text {Cre }}$ and $A s c l{ }^{C r e E R}$ revealed that Ascl1 plays an additional role in ensuring proper segregation of cells to the vz rather than the url specifically during the time when Pcs are generated. In contrast to Ptf1a that plays an "all-or-nothing" role in generation of cerebellar GABAergic cell types, Ascl1 thus plays temporally dynamic and multifaceted roles in regulating the generation of the correct balance of all cerebellar inhibitory neurons and glia.

\section{Model for constructing the cerebellar microcircuitry}

We propose a temporal model and rationale for building the local cerebellar circuitry (Fig. 9) that is based on our finding that all but the astrocytes and oligodendrocytes have distinct temporal origins as well as previous studies that delineated the temporal origins of url-derived neurons (Wang and Zoghbi, 2001; Machold and Fishell, 2005). The main efferent neurons are the first cells of the cerebellar circuitry to be established followed by the neurons that project to (GABAergic cells of the $\mathrm{cn}$ and Pcs between E10.5 and E12.5). Interestingly, the first Pcs to be born are those that settle in the lateral cerebellum where efferent Pcs project directly outside the cerebellum (to the vestibular nuclei). The next cell type generated is the Bergmann glia $(\sim$ E13.5), which are critical for gc migration (starting at $\sim$ E17.5), Pc dendrite growth, and organization of $\mathrm{ml}$ interneuron axons (Rakic and Sidman, 1973; 
Hatten and Mason, 1990; Gao and Hatten, 1993; Lordkipanidze and Dunaevsky, 2005; Ango et al., 2008). Granule and Golgi cells, which form the glomeruli in the igl, are the next neurons generated. The basket interneurons, which synapse with Pc bodies and apical stem dendrites (Altman and Bayer, 1997), are then preferentially generated before the stellate interneurons that synapse with the later forming Pc distal dendrites (Altman and Bayer, 1997). While the exact role remains unknown of candelabrum interneurons in cerebellar circuitry, it is tempting to speculate that they contact Pc dendrites throughout the width of the $\mathrm{ml}$, as their own projections run parallel with Pc dendrites and we found they express Ascl1 ${ }^{\mathrm{CreER}}$ when the Pc dendrites begin to form. Finally, oligodendrocytes and astrocytes are primarily generated after birth, once their target cells are in place. Thus, there is a predictable sequence of generation of cells in the cerebellum, with target neurons being born before their regulatory cells. This is in contrast to mossy fiber neurons that are born long before their targets, the gcs, have formed the igl.

\section{References}

Altman J, Bayer SA (1997) Development of the cerebellar system in relation to its evolution, structure, and functions. New York: CRC.

Ango F, Wu C, Van der Want JJ, Wu P, Schachner M, Huang ZJ (2008) Bergmann glia and the recognition molecule CHL1 organize GABAergic axons and direct innervation of Purkinje cell dendrites. PLoS Biol 6:e103.

Barmack NH, Yakhnitsa V (2008) Functions of interneurons in mouse cerebellum. J Neurosci 28:1140-1152.

Bastianelli E (2003) Distribution of calcium-binding proteins in the cerebellum. Cerebellum 2:242-262.

Battiste J, Helms AW, Kim EJ, Savage TK, Lagace DC, Mandyam CD, Eisch AJ, Miyoshi G, Johnson JE (2007) Ascll defines sequentially generated lineage-restricted neuronal and oligodendrocyte precursor cells in the spinal cord. Development 134:285-293.

Casarosa S, Fode C, Guillemot F (1999) Mash1 regulates neurogenesis in the ventral telencephalon. Development 126:525-534.

Celio MR (1990) Calbindin D-28K and parvalbumin in the rat nervous system. Neuroscience 35:375-475.

Doetsch F (2003) The glial identity of neural stem cells. Nat Neurosci 6:1127-1134.

Englund C, Kowalczyk T, Daza RA, Dagan A, Lau C, Rose MF, Hevner RF (2006) Unipolar brush cells of the cerebellum are produced in the rhombic lip and migrate through developing white matter. J Neurosci 26:9184-9195.

Gao WQ, Hatten ME (1993) Neuronal differentiation rescued by implantation of Weaver granule cell precursors into wild-type cerebellar cortex. Science 260:367-369.

Grimaldi P, Parras C, Guillemot F, Rossi F, Wassef M (2009) Origins and control of the differentiation of inhibitory interneurons and glia in the cerebellum. Dev Biol 328:422-433.

Guillemot F, Joyner AL (1993) Dynamic expression of the murine AchaeteScute homologue Mash-1 in the developing nervous system. Mech Dev 42:171-185.

Guillemot F, Lo LC, Johnson JE, Auerbach A, Anderson DJ, Joyner AL (1993) Mammalian achaete-scute homolog 1 is required for the early development of olfactory and autonomic neurons. Cell 75:463-476.

Hashimoto M, Mikoshiba K (2003) Mediolateral compartmentalization of the cerebellum is determined on the "birth date" of Purkinje cells. J Neurosci 23:11342-11351.

Hatten ME, Mason CA (1990) Mechanisms of glial-guided neuronal migration in vitro and in vivo. Experientia 46:907-916.

Helms AW, Battiste J, Henke RM, Nakada Y, Simplicio N, Guillemot F, Johnson JE (2005) Sequential roles for Mash1 and Ngn2 in the generation of dorsal spinal cord interneurons. Development 132:2709-2719.

Hoshino M, Nakamura S, Mori K, Kawauchi T, Terao M, Nishimura YV, Fukuda A, Fuse T, Matsuo N, Sone M, Watanabe M, Bito H, Terashima T, Wright CV, Kawaguchi Y, Nakao K, Nabeshima Y (2005) Ptfla, a bHLH transcriptional gene, defines GABAergic neuronal fates in cerebellum. Neuron 47:201-213.

Joyner AL, Zervas M (2006) Genetic inducible fate mapping in mouse: es- tablishing genetic lineages and defining genetic neuroanatomy in the nervous system. Dev Dyn 235:2376-2385.

Kawaguchi Y, Cooper B, Gannon M, Ray M, MacDonald RJ, Wright CV (2002) The role of the transcriptional regulator Ptfla in converting intestinal to pancreatic progenitors. Nat Genet 32:128-134.

Kim EJ, Leung CT, Reed RR, Johnson JE (2007) In vivo analysis of Ascll defined progenitors reveals distinct developmental dynamics during adult neurogenesis and gliogenesis. J Neurosci 27:12764-12774.

Kim EJ, Battiste J, Nakagawa Y, Johnson JE (2008) Ascl1 (Mash1) lineage cells contribute to discrete cell populations in CNS architecture. Mol Cell Neurosci 38:595-606.

Kim EJ, Ables JL, Dickel LK, Eisch AJ, Johnson JE (2011) Ascl1 (Mash1) defines cells with long-term neurogenic potential in subgranular and subventricular zones in adult mouse brain. PLoS One 6:e18472.

Kimmel RA, Turnbull DH, Blanquet V, Wurst W, Loomis CA, Joyner AL (2000) Two lineage boundaries coordinate vertebrate apical ectodermal ridge formation. Genes Dev 14:1377-1389.

Lainé J, Axelrad H (1994) The candelabrum cell: a new interneuron in the cerebellar cortex. J Comp Neurol 339:159-173.

Larouche M, Hawkes R (2006) From clusters to stripes: the developmental origins of adult cerebellar compartmentation. Cerebellum 5:77-88.

Legué E, Joyner AL (2010) Genetic fate mapping using site-specific recombinases. Methods Enzymol 477:153-181.

Leto K, Bartolini A, Yanagawa Y, Obata K, Magrassi L, Schilling K, Rossi F (2009) Laminar fate and phenotype specification of cerebellar GABAergic interneurons. J Neurosci 29:7079-7091.

Li JY, Joyner AL (2001) Otx2 and Gbx2 are required for refinement and not induction of mid-hindbrain gene expression. Development 128:4979-4991.

Li JY, Lao Z, Joyner AL (2005) New regulatory interaction and cellular responses in the isthmic organizer region revealed by altering $\mathrm{Gbx} 2$ expression. Development 132:1971-1981.

Lin SC, Bergles DE (2004) Synaptic signaling between neurons and glia. Glia 47:290-298.

Lordkipanidze T, Dunaevsky A (2005) Purkinje cell dendrites grow in alignment with Bergmann glia. Glia 51:229-234.

Machold R, Fishell G (2005) Math1 is expressed in temporally discrete pools of cerebellar rhombic-lip neural progenitors. Neuron 48:17-24.

Mathis C, Collin L, Borrelli E (2003) Oligodendrocyte ablation impairs cerebellum development. Development 130:4709-4718.

Milosevic A, Goldman JE (2002) Progenitors in the postnatal cerebellar white matter are antigenically heterogeneous. J Comp Neurol 452:192-203.

Milosevic A, Goldman JE (2004) Potential of progenitors from postnatal cerebellar neuroepithelium and white matter: lineage specified vs. multipotent fate. Mol Cell Neurosci 26:342-353.

Nakada Y, Hunsaker TL, Henke RM, Johnson JE (2004) Distinct domains within Mash1 and Math1 are required for function in neuronal differentiation versus neuronal cell-type specification. Development 131:1319-1330.

Newman EA (2003) New roles for astrocytes: regulation of synaptic transmission. Trends Neurosci 26:536-542.

Nguyen MT, Zhu J, Nakamura E, Bao X, Mackem S (2009) Tamoxifendependent, inducible Hoxb6CreERT recombinase function in lateral plate and limb mesoderm, CNS isthmic organizer, posterior trunk neural crest, hindgut, and tailbud. Dev Dyn 238:467-474.

Pacary E, Heng J, Azzarelli R, Riou P, Castro D, Lebel-Potter M, Parras C, Bell DM, Ridley AJ, Parsons M, Guillemot F (2011) Proneural transcription factors regulate different steps of cortical neuron migration through Rndmediated inhibition of RhoA signaling. Neuron 69:1069-1084.

Parras CM, Galli R, Britz O, Soares S, Galichet C, Battiste J, Johnson JE, Nakafuku M, Vescovi A, Guillemot F (2004) Mash1 specifies neurons and oligodendrocytes in the postnatal brain. EMBO J 23:4495-4505.

Parras CM, Hunt C, Sugimori M, Nakafuku M, Rowitch D, Guillemot F (2007) The proneural gene Mash1 specifies an early population of telencephalic oligodendrocytes. J Neurosci 27:4233-4242.

Pascual M, Abasolo I, Mingorance-Le Meur A, Martínez A, Del Rio JA, Wright CV, Real FX, Soriano E (2007) Cerebellar GABAergic progenitors adopt an external granule cell-like phenotype in the absence of Ptfla transcription factor expression. Proc Natl Acad Sci U S A 104:5193-5198.

Pattyn A, Guillemot F, Brunet JF (2006) Delays in neuronal differentiation in Mash1/Ascl1 mutants. Dev Biol 295:67-75. 
Rakic P (1971) Neuron-glia relationship during granule cell migration in developing cerebellar cortex. A Golgi and electronmicroscopic study in Macacus rhesus. J Comp Neurol 141:283-312.

Rakic P (1973) Kinetics of proliferation and latency between final cell division and onset of differentiation of cerebellar stellate and basket neurons. J Comp Neurol 147:523-546.

Rakic P, Sidman RL (1973) Sequence of developmental abnormalities leading to granule cell deficit in cerebellar cortex of weaver mutant mice. J Comp Neurol 152:103-132.

Shiga T, Ichikawa M, Hirata Y (1983) Spatial and temporal pattern of postnatal proliferation of Bergmann glial cells in rat cerebellum: an autoradiographic study. Anat Embryol (Berl) 167:203-211.

Sillitoe RV, Joyner AL (2007) Morphology, molecular codes and circuitry produce the three dimensional complexity of the cerebellum. Annu Rev Cell Dev Biol 23:549-577.

Sillitoe RV, Vogel MW, Joyner AL (2010) Engrailed homeobox genes regulate establishment of the cerebellar afferent circuit map. J Neurosci 30:10015-10024.

Soriano P (1999) Generalized lacZ expression with the ROSA26 Cre reporter strain. Nat Genet 21:70-71.

Srinivas S, Watanabe T, Lin CS, William CM, Tanabe Y, Jessell TM, Costantini F (2001) Cre reporter strains produced by targeted insertion of EYFP and ECFP into the ROSA26 locus. BMC Dev Biol 1:4.

Sugimori M, Nagao M, Bertrand N, Parras CM, Guillemot F, Nakafuku M
(2007) Combinatorial actions of patterning and HLH transcription factors in the spatiotemporal control of neurogenesis and gliogenesis in the developing spinal cord. Development 134:1617-1629.

Ullian EM, Sapperstein SK, Christopherson KS, Barres BA (2001) Control of synapse number by glia. Science 291:657-661.

Wang VY, Zoghbi HY (2001) Genetic regulation of cerebellar development. Nat Rev Neurosci 2:484-491.

Wildner H, Müller T, Cho SH, Bröhl D, Cepko CL, Guillemot F, Birchmeier C (2006) dILA neurons in the dorsal spinal cord are the product of terminal and non-terminal asymmetric progenitor cell divisions, and require Mash 1 for their development. Development 133:2105-2113.

Yamada K, Fukaya M, Shibata T, Kurihara H, Tanaka K, Inoue $\mathrm{Y}$, Watanabe M (2000) Dynamic transformation of Bergmann glal fibers proceeds in correlation with dendritic outgrowth and synapse formation of cerebellar Purkinje cells. J Comp Neurol 418:106-120.

Zhang L, Goldman JE (1996a) Generation of cerebellar interneurons from dividing progenitors in white matter. Neuron 16:47-54.

Zhang L, Goldman JE (1996b) Developmental fates and migratory pathways of dividing progenitors in the postnatal rat cerebellum. J Comp Neurol 370:536-550.

Zordan P, Croci L, Hawkes R, Consalez GG (2008) Comparative analysis of proneural gene expression in the embryonic cerebellum. Dev Dyn 237: $1726-1735$. 